NBER WORKING PAPER SERIES

\title{
AIR POLLUTION AND ADULT COGNITION: EVIDENCE FROM BRAIN TRAINING
}

\author{
Andrea La Nauze \\ Edson R. Severnini \\ Working Paper 28785 \\ http://www.nber.org/papers/w28785
NATIONAL BUREAU OF ECONOMIC RESEARCH
1050 Massachusetts Avenue \\ Cambridge, MA 02138 \\ May 2021, Revised November 2021
}

We thank Karen Clay, and seminar/conference participants at the Australian National University, Carnegie Mellon University, Cornell University, Lumos Labs, Inc., and the University of Adelaide for invaluable comments and suggestions. The authors gratefully acknowledge financial support from the University of Pittsburgh and the Heinz College at Carnegie Mellon University. The views expressed herein are those of the authors and do not necessarily reflect the views of the National Bureau of Economic Research.

NBER working papers are circulated for discussion and comment purposes. They have not been peerreviewed or been subject to the review by the NBER Board of Directors that accompanies official NBER publications.

(C) 2021 by Andrea La Nauze and Edson R. Severnini. All rights reserved. Short sections of text, not to exceed two paragraphs, may be quoted without explicit permission provided that full credit, including (C) notice, is given to the source. 
Air Pollution and Adult Cognition: Evidence from Brain Training Andrea La Nauze and Edson R. Severnini

NBER Working Paper No. 28785

May 2021, Revised November 2021

JEL No. I14,I24,J24,Q53

\title{
ABSTRACT
}

We exploit novel data from brain-training games to examine the impacts of air pollution on a comprehensive set of cognitive skills in adults. We find that exposure to particulate matter (PM2.5) impairs adult cognitive function, and that these effects are largest for those in prime working age. These results confirm a hypothesized mechanism for the impacts of air pollution on workforce productivity. We also find that the cognitive effects are largest for new tasks and for those with low ability, suggesting that air pollution increases inequality in productivity.

\author{
Andrea La Nauze \\ Level 6, Colin Clark Building \\ Brisbane, QLD 4072 \\ Australia \\ a.lanauze@uq.edu.au \\ Edson R. Severnini \\ H. John Heinz III College \\ Carnegie Mellon University \\ 4800 Forbes Ave \#2114B \\ Pittsburgh, PA 15213 \\ and NBER \\ ersevernini@gmail.com
}




\section{Introduction}

Besides being harmful to human health, ${ }^{1}$ exposure to air pollution is detrimental to human capital formation, ${ }^{2}$ and labor productivity. ${ }^{3}$ In principle, these detrimental effects may be the result of a decline in cognitive skills such as attention, memory, speed of information processing, and problem solving. To date, however, data availability has been a particular obstacle to this line of research (Graff Zivin and Neidell, 2013). As such, prior studies have focused on secondary measures of cognition using scholastic achievement, or coarse measures of performance in cognitively-demanding settings. The accumulated evidence therefore arises either from school-age groups, or from a limited set of specific sites, industries and tasks. Yet, when impacts are heterogeneous such studies may fail to identify effects relevant to the broader population (Hsiang, Oliva and Walker, 2019).

In this study, we examine the impacts of air pollution exposure on direct measures of cognitive performance using Lumosity brain games over the period 2015-2017. Lumosity is a widely-used, freely available online platform offering games aimed at improving attention, memory, flexibility, speed of processing, and problem solving. It takes scientifically-validated tasks and turns them into games that are accessible to any age or skill level. Through an agreement with Lumos Labs, Inc., we obtained access to proprietary user-level data for each play across seven games, totaling over 4.6 million user-play observations. These detailed data allow us to exploit daily variation in fine particulate matter (PM2.5) within a 3-digit ZIP code area to identify the effects of air pollution on a comprehensive set of cognitive domains across age groups and levels of cognitive ability. Despite being a non-randomly selected

\footnotetext{
${ }^{1}$ See, for example, Chay and Greenstone (2003); Currie and Neidell (2005); Currie and Walker (2011); Graff Zivin and Neidell (2013); Currie et al. (2014, 2015); Schlenker and Walker (2016); Deschenes, Greenstone and Shapiro (2017); Deryugina et al. (2019).

${ }^{2}$ See, for example, Currie et al. (2009); Sanders (2012); Miller and Vela (2013); Ham, Zweig and Avol (2014); Stafford (2015); Ebenstein, Lavy and Roth (2016); Bharadwaj et al. (2017); Marcotte (2017); Austin, Heutel and Kreisman (2019); Chen (2019); Shehab and Pope (2019); Gilraine (2020); Roth (2020); Heissel, Persico and Simon (Forthcoming); Persico and Venator (Forthcoming).

${ }^{3}$ See, for example, Graff Zivin and Neidell (2012, 2013); Hanna and Oliva (2015); Chang et al. (2016); Heyes, Neidell and Saberian (2016); Fu, Viard and Zhang (2017); Meyer and Pagel (2017); Archsmith, Heyes and Saberian (2018); Chang et al. (2019); He, Liu and Salvo (2019); Huang, Xu and Yu (2020); Adhvaryu, Kala and Anant (2021).
} 
sample, the data allow us to expand the analysis beyond the current state of knowledge to assess the adverse effects of pollution across age groups in the U.S. population. Most previous studies have focused on the young and the elderly.

There are two well-known challenges to identifying causal impacts of pollution exposure. First, ex-post pollution exposure is not random: for example, individuals may sort into residential areas in part based on environmental quality (e.g., Chay and Greenstone, 2005; Banzhaf and Walsh, 2008). Our identification relies only on short-term changes in pollution exposure within an individual's play history. Second, there may be important disconnections between where individuals live and work and where pollution is measured, leading to serious measurement error issues (e.g., Moretti and Neidell, 2011). Inspired by Deryugina et al. (2019), we address this concern by instrumenting for daily PM2.5 concentrations using daily changes in local wind direction. Our instrument is an indicator variable for whether the daily local wind direction is at the direction associated with the maximum potential for the transport of pollutants from other locations. ${ }^{4}$ The exclusion restriction is that, after flexibly controlling for many fixed effects and climatic variables, changes in an area's daily wind direction have no direct effect on performance in brain games except through their influence on air pollution.

Our IV estimates indicate that exposure to PM2.5 at levels above $25 \mu \mathrm{g} / \mathrm{m}^{3}$ reduces standardized scores in brain games by approximately 0.18 standard deviations. The threshold was World Health Organization (WHO) air quality guideline value for 24-hour exposure to PM2.5 at the time of the sample, but still $10 \mu \mathrm{g} / \mathrm{m}^{3}$ below the U.S. National Ambient Air Quality Standards (NAAQS) for PM2.5 over 24 hours. The estimated effect has meaningful implications for the U.S. population: it is equivalent to a reduction of 5.8 percentiles in the distribution of scores reweighted to match the characteristics of the population. ${ }^{5}$ Across the

\footnotetext{
${ }^{4}$ We also provide comparisons between estimates using this instrument and those using the full set of wind direction instruments à la Deryugina et al. (2019).

${ }^{5}$ To construct this distribution, for each game, Lumosity resamples from their user base to match age, gender and education of the US population from the 2010 U.S. Census. For reference, in our Lumosity sample the proportion of females is $58.5 \%$, the proportion of individuals 65 years and older is $19.1 \%$, and the proportion of college graduates is 66.3\%. In the 2015-2019 American Community Survey (ACS), those proportions
} 
seven cognitive domains considered by Lumosity and included in our analysis, the effects on memory are strongest but there is suggestive evidence that problem solving may also be affected. Furthermore, the results appear to be substantially larger for individuals in prime working age - those under the age of 50. Psychologists suggest that younger people rely more on fluid intelligence - that part of intelligence that is independent of learning and accumulated knowledge - which our results suggest could be more affected by short-term exposure to fine particulates. ${ }^{6}$ Taken together, these findings suggest that occupations that require memory and problem solving may be more affected by PM2.5, and these effects may be more detrimental in younger workers or those more reliant on fluid intelligence.

The results also indicate important heterogeneity by experience and cognitive ability. The adverse effects of PM2.5 are stronger the first five times that individuals play the Lumosity games. On the other hand, there does not appear to be any difference in the performance of more experienced players. The effects also tend to be more detrimental for individuals in the lower quintiles of the distribution of cognitive ability, as implied by their initial performance. Overall, these patterns suggest that air pollution may increase inequality by affecting the acquisition of skills, and by increasing the divide between low- and high-skilled individuals.

This study makes two main contributions to the literature. First, it opens up the black box regarding the effects of air pollution on cognitive function, shedding light on potential mechanisms behind prior findings on the impacts on scholastic achievement and labor productivity (e.g., Ebenstein, Lavy and Roth, 2016; Archsmith, Heyes and Saberian, 2018; Chang et al., 2019; Heissel, Persico and Simon, 2020). It also helps rationalize the mixed results from different industries and occupations (e.g., Chang et al., 2016, 2019; He, Liu and Salvo, 2019; Huang, $\mathrm{Xu}$ and $\mathrm{Yu}, 2020) .{ }^{7}$ This is accomplished with a relatively large are $50.8 \%, 16.5 \%$, and $32.1 \%$, respectively (see www.census.gov/quickfacts/fact/table/US/PST045219).

${ }^{6}$ Older individuals rely more on crystallized intelligence - that part of intelligence that comes from learned procedures and knowledge - which in theory should be less affected by short-term pollution exposure. Also, note that on average younger people outperform older people, consistent with age-related cognitive decline, but that individual fixed effects control for these age group effects.

${ }^{7}$ The estimated impact on memory may also provide a mechanism behind the causal effect of sustained exposure to PM2.5 on dementia among the Medicare population (Bishop, Ketcham and Kuminoff, 2018). 
sample of individuals across many locations, likely enhancing external validity relative to most previous settings, which are from a small number of facilities or limited age groups. The closest paper to ours is Bedi et al. (2021), which also examines the impact of PM2.5 on various cognitive domains, but their sample consists of 464 students from a university in Brazil who engaged in 54 lab sessions over a 3-year period. Krebs and Luechinger (2021) also use Lumosity data to examine the effect of nitrogen oxides (NOx) on cognitive performance, but focus on a mental arithmetic game.

The second contribution relates to the role of pollution in furthering inequality in health, education, and labor market outcomes. One dimension of inequality arises from disproportionate exposure to pollution, as documented by the environmental justice literature (Banzhaf, Ma and Timmins, 2019a,b; Heblich, Trew and Zylberberg, 2021). Another dimension may be disproportionate impacts (Hsiang, Oliva and Walker, 2019). Here we provide evidence that even under similar levels of pollution, low-skilled and less-experienced individuals might be more affected by PM2.5. These findings highlight the potential for environmental insults to exacerbate the gaps observed in health, education, and labor market outcomes.

\section{Background}

\section{A. Air pollution and cognitive function}

There is growing evidence that exposure to air pollution is associated with impaired cognitive functions at all ages (e.g., Kilian and Kitazawa, 2018; Paul et al., 2019; Schikowski and Altuğ, 2020). The adverse effects of particulate matter (PM) on the nervous system may be a result of a direct route to the brain or stimulation of pro-inflammatory cytokines via an indirect route. PM has implications for oxidative stress, inflammation, dysfunction of cellular organelles, as well as the disturbance of protein homeostasis, promoting neuron loss and exaggerating the burden of central nervous system (Allen et al., 2017; Wang, Xiong and 
Tang, 2017). Acute exposure to PM can also alter properties of glutamate receptors that are critical to neuronal plasticity and memory processes (Davis et al., 2013).

Older adults living in areas with higher PM2.5 concentrations have been shown to experience worse cognitive function even after adjustment for social and economic characteristics. In a landmark study, Ailshire and Crimmins (2014) analyzed data from the 2004 Health and Retirement Study, a large, nationally representative sample of U.S. adults aged 50 years or older, and found that the association is strongest for the episodic memory component of cognitive function. PM2.5 has also been associated with greater declines in immediate recall and new learning in a recent study involving older females (Younan et al., 2019). Using quasi-random variation in pollution exposure due to the EPA's 2005 designation of nonattainment counties for PM2.5, Bishop, Ketcham and Kuminoff (2018) analyzed fifteen years of Medicare records on 6.9 million U.S. residents over age 65 to estimate the causal impact of particulate matter on dementia. They found that a $1 \mu \mathrm{g} / \mathrm{m}^{3}$ increase in average decadal exposure causally increases the probability of receiving a dementia diagnosis by 1.3 percentage points, or $6.7 \%$ of the mean.

There is also evidence that cognitive function in younger individuals is affected by exposure to particulate matter. Air pollution shocks have been shown to reduce student performance from elementary school to college (e.g., Miller and Vela, 2013; Stafford, 2015; Ebenstein, Lavy and Roth, 2016; Roth, 2020). In the study closest to ours, Bedi et al. (2021) examined the impact of short-term exposure to PM2.5 on the cognitive performance of students from a Brazilian university. Exploiting plausibly exogenous variation in indoor pollution across 54 lab sessions over a 3-year period with 464 students, they found that high levels of PM2.5 reduce performance on a fluid reasoning test, but were underpowered to detect effects on other cognitive domains such as simple attention, complex attention, arithmetic processing speed, and working memory. Regarding the overall adult population, Zhang, Chen and Zhang (2018) analyzed data from a nationally representative longitudinal survey in China, and found that long-term exposure to air pollution impedes cognitive per- 
formance in verbal and math tests. They also documented that the effect on verbal tests becomes more pronounced as people age, especially for men and the less educated.

In summary, while there are strong associations between cognition and exposure to particular matter across the age distribution, causal evidence is largely limited to performance of students or long term cognitive decline in the elderly.

\section{B. Brain training and cognitive function}

In this study we measure cognitive function via performance in Lumosity games. But does performance in brain training reflect transferable cognitive skills? Put differently, do changes in game scores, for example due to dedicated training, reflect changes in cognitive functions such as problem solving? These are long-standing questions in behavioral science. A recent systematic review of brain-training, or "brain games," has found extensive evidence that they improve performance on trained tasks (Simons et al., 2016). Furthermore, "[i]t is uncontested that training programs can lead to near transfer, meaning increased performance on untrained tasks involving similar cognitive functions" (Smid, Karbach and Steinbeis, 2020, p. 531).

The most extensive review to date of interventions to improve executive functions - which include attention, working memory, cognitive flexibility, and reasoning - also highlights the impact of training and transfer of this improvement to similar tasks (Diamond and Ling, 2020). Taken together, these reviews suggest that performance scores in brain training do measure cognitive skills. Furthermore, the reviews note that the length, frequency, spacing and difficulty of the training, combined with baseline ability of the subjects, all determine its efficacy. These lessons help us inform our empirical strategy and the interpretation of our results. $^{8}$

\footnotetext{
${ }^{8}$ In Appendix B, we also present a conceptual framework underlying the mechanisms through which pollution may affect cognitive function, including biological channels and behavioral responses.
} 


\section{Data}

Our primary data are anonymized game performance scores from the brain training company Lumos Labs. This company is the owner of Lumosity, which gives users access to brain training games and analytics on both web based and phone application platforms. Our data include scores from the seven Lumosity games outlined in Appendix Table A.1. These games were selected by Lumos because game design and usage were relatively stable over time, and to ensure that the combination of games spanned the breadth of cognitive domains - verbal, attention, flexibility, memory, math, speed, and problem solving.

For each game we observe timestamps and scores for all users who signed up for Lumosity and played between 5 and 50 times on the web based platform during the period 2015-2017. We also observe each user's location at the 3-digit ZIP code at the time the user signed up for Lumosity, which is derived by Lumos from a user's IP address. ${ }^{9}$ In addition, we observe self reported characteristics of users including age, gender, and education, and additional data collected by Lumos including an identifier for whether the user is a paid subscriber, the date the user joined Lumosity, and any dates that the users played games outside our sample. ${ }^{10}$

We use the centroid of each ZIP code to match game data to the U.S. EPA Air Quality Monitoring System - matching to any monitor within 20 miles of the centroid - and to weather observations from the Integrated Surface Database (ISD) from the National Centers for Environmental Information - matching to any station within 30 miles of the centroid. ${ }^{11}$ Appendix Figure A.2 maps the distribution of the 116,495 users in the estimation sample. They are scattered around the nation, with heavy concentrations in the West coast, where Lumos Labs are headquartered (San Francisco, CA).

\footnotetext{
${ }^{9}$ For convenience, the 3-digit ZIP code areas in the United States are displayed in Appendix Figure A.1.

${ }^{10}$ Summary statistics are reported in Appendix Table A.2. Subscription provides users with access to additional analytics and games.

${ }^{11}$ The results are qualitatively the same for matching to air quality monitors within 30 miles.
} 
To enable comparisons across games, we standardize scores in the following way:

$$
S_{i g t}=\frac{\text { Raw_Score }_{i g t}-\overline{\text { Raw_Score }_{g}}}{\sigma_{g}}
$$

where $S_{i g t}$ is the standardized score of user $i$ in game $g$ at time $t$, Raw_Score $_{\text {igt }}$ is the raw score provided by Lumosity, $\overline{\text { Raw_Score }_{g}}$ is the mean raw score across all players and plays in game $g$, and $\sigma_{g}$ is the standard deviation of raw scores in game $g$.

\section{Empirical Strategy}

To estimate the impact of air pollution exposure on cognition, we use the following equation:

$$
S_{i t}=\beta \mathbf{1}\left[P M 2.5_{z d m y}>25\right]+X_{z d m y}^{\prime} \gamma+\alpha_{i}+\alpha_{m y}+\epsilon_{i t}
$$

where $S$ is the standardized score for player $i$ in 3-digit ZIP code $z$, at time $t$ of day $d$, month $m$, and year $y . \mathbf{1}\left[P M 2.5_{z d m y}>25\right]$ is an indicator variable equal to one if the level of PM2.5 is above $25 \mu \mathrm{g} / \mathrm{m}^{3}$. This threshold is the World Health Organization (WHO) air quality guideline value for 24-hour exposure to PM2.5, but still $10 \mu \mathrm{g} / \mathrm{m}^{3}$ below the U.S. National Ambient Air Quality Standards (NAAQS) for PM2.5 over 24 hours. The $25 \mu \mathrm{g} / \mathrm{m}^{3}$ cutoff is above the ninety-ninth percentile of the distribution of particulates in our sample, but far below the maximum daily concentration in our sample - about $270 \mu \mathrm{g} / \mathrm{m}^{3}{ }^{12}{ }^{12} \alpha_{i}$ represents player fixed effects, $\alpha_{m y}$ month-by-year fixed effects, and $X_{z d m y}$ control variables - wind speed, precipitation, and bins of daily maximum temperature. ${ }^{13}$

We face two primary empirical challenges in estimating $\beta$. First, individuals choose when to play brain training games and this choice may be directly or indirectly related to pollution levels. If, for example, pollution does have an effect on cognitive ability, and this effect is noticeable to participants, they may be more or less likely to decide to play Lumosity games.

\footnotetext{
${ }^{12}$ The distribution of daily PM2.5 in our sample is displayed in Appendix Figure A.3.

${ }^{13}$ In the results section, we explore the sensitivity of our estimates to alternative structure of fixed effects, alternative thresholds for the indicator variable for exposure to PM2.5, and outliers.
} 
This would be problematic if, for example, users who have low cognitive ability are more affected by pollution and choose not to play on days when they feel its effects. Appendix Figure A.4, however, shows PM2.5 does not affect the number or composition of players.

The second empirical challenge in estimating $\beta$ is measurement error. Measurement error arises due to the sparsity of the monitoring network, and the fact that actual pollution exposure can vary over very short distances based on proximity to large roads or other local sources of pollution. Measurement error causes attenuation bias leading us to understate the impact of pollution on cognition.

We build on the approach of Deryugina et al. (2019) using an instrument based on changes in wind direction. The idea of the instrument is to isolate variation in non-local pollution that is transported by wind. This variation in pollution exposure should have a uniform effect within a locality and be orthogonal to differences in exposure to local sources. The specification for our first stage is

$$
\begin{aligned}
\mathbf{1}\left[P M 2.5_{z d m y}>25\right] & =\theta \mathbf{1}\left[\text { WindDir }_{z d m y}=\max P M 2.5_{-} \text {WindDir }_{z_{2} m}\right] \\
& +X_{z d m y}^{\prime} \delta+\alpha_{i}+\alpha_{m y}+\epsilon_{i d m y} .
\end{aligned}
$$

The excluded instrument is the variable $\mathbf{1}\left[\right.$ WindDir $_{z d m y}=\max$ M2.5_WindDir $\left.r_{z_{2} m}\right]$. This indicator variable is equal to one if the daily average wind direction in the 3-digit ZIP code $z$ falls in the 60-degree interval that usually brings the highest levels of PM2.5 to the more aggregated 2-digit ZIP code region $z_{2}$ in month $m$. The wind directions associated with the maximum pollution levels for each region-month are found in preliminary regressions estimated separately for each of the 99 2-digit zips. In these regressions the dependent variable is $\mathbf{1}\left[P M 2.5_{z d m y}>25\right]$, the parameters of interest are the coefficients on indicator variables for the interaction between binned wind direction and calendar month, the same

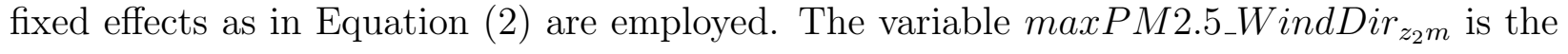
wind direction with the largest coefficient for each calendar month. ${ }^{14}$

\footnotetext{
${ }^{14}$ This procedure may avoid weak instrument issues that might emerge when including all interactions be-
} 


\section{Results}

\section{A. Average Impacts of Exposure to PM2.5 on Cognitive Function}

Table 1 reports the average impacts of exposure to fine particulate matter (PM2.5) on cognitive function as measured by standardized scores in Lumosity games. Columns 1 and 2 in Panel A present the OLS estimates using PM2.5 measured in levels or as a dummy for relatively high concentrations - above $25 \mu \mathrm{g} / \mathrm{m}^{3}$ - respectively. Columns 3 and 4 display the corresponding IV estimates. Lastly, columns 5 and 6 present IV estimates for an alternative outcome variable: the percentile of an individual's score in the overall distribution of scores adjusted to match the characteristics of the U.S. population. The Kleibergen-Paap rk Wald F statistics from the first stage in the IV specifications are all above the Staiger and Stock (1997) rule-of-thumb cutoff of 10, suggesting that the excluded instrument is strong.

Our preferred estimate in column 4 indicates that exposure to relatively high levels of PM2.5 reduces standardized scores by about 0.18 of a standard deviation. ${ }^{15}$ This effect is relatively large. For comparison, Ebenstein, Lavy and Roth (2016) find that the effect of PM2.5 on Israeli high-school student scores for the ninety-ninth percentile of exposure in their sample (about $50 \mu \mathrm{g} / \mathrm{m}^{3}$ ) implies a decline of roughly 0.13 of a standard deviation in scores relative to an average day's air quality (about $\left.16 \mu \mathrm{g} / \mathrm{m}^{3}\right) .{ }^{16}$ Our estimate is also

tween the 60-degree intervals and the $z_{2}$ regions in the first stage. Furthermore, unlike an over-identified 2SLS model, the just-identified 2SLS is approximately median unbiased even with a relatively weak instrument. We compare estimates arising from alternative instruments in the results section.

${ }^{15}$ If we instrument PM2.5 with interactions of 100 clusters of pollution monitors and 60-degree wind direction bins à la Deryugina et al. (2019), we cannot rule out that the IV estimate for PM measured in levels is statistically identical to the corresponding estimate using our instrument, as shown in Appendix Table A.3, column 1. For models with an indicator of PM above the annual NAAQS threshold $\left(12 \mu \mathrm{g} / \mathrm{m}^{3}\right)$, the results are still qualitatively similar, as reported in column 2. For a higher threshold, however, the IV estimate using the full set of instruments becomes insignificant, as shown in column 3, Panel B. The first-stage F statistic decreases considerably, suggesting the presence of weak instruments among the full set of instruments. In contrast, our instrument remains relatively strong even in the case of a more extreme threshold, as shown in column 3, Panel A.

${ }^{16}$ Another comparison to put the magnitude of our estimates into perspective: Ebenstein, Lavy and Roth (2016) find that a test score in an exam on a day with average pollution (about $16 \mu \mathrm{g} / \mathrm{m}^{3}$ ) will be lowered relative to an exam taken on a day with the minimum pollution level (about $2.4 \mu \mathrm{g} / \mathrm{m}^{3}$ ) by 0.083 standard deviations. Recall that they use data for every SAT-equivalent test taker in Israel from 2000-2002. Our estimate in Table 1, Panel B, column 5, shows a reduction of 0.15 of a standard deviation when Lumosity users nationwide are exposed to levels of PM2.5 above $15 \mu \mathrm{g} / \mathrm{m}^{3}$ relative to exposure below that threshold. 
equivalent to a reduction of 5.8 percentiles in the distribution of scores adjusted to match the characteristics of the U.S. population, as reported in column 6 .

Panel B of Table 1 reports a number of robustness and specification checks. Column 1 replaces user fixed effects in Equation (2) with user-by-hour fixed effects, and includes day-ofweek fixed effects. This alternative specification addresses concerns associated with selection of users into playing in particular hours or days of the week. As an example, working-age users may play in the evenings and weekends, and retirees may play during the day in weekdays. Column 2 adds to our main specification day-of-week and 2-digit ZIP code-bymonth fixed effects, to control more flexibly for spatial and seasonal variation in game playing. Column 3 adds a lag and lead of the high PM2.5 indicator to our main specification, to check for delayed effects of pollution and spurious effects, respectively. Column 4 constrains the sample to include only observations with PM2.5 below $35 \mu \mathrm{g} / \mathrm{m}^{3}$ - the current 24-hour NAAQS for PM2.5 - to avoid the potential influence of outliers. This alternative sample also allows us to test for PM2.5 effects only among levels of exposure below the current air quality standards. In all these four columns, the causal effect of exposure to relatively high levels of fine particulate matter is quantitatively similar to our main estimate in Panel A, column 4.

The last two columns of Table 1, Panel B, display the estimates associated with alternative cutoffs for exposure to fine particulates. Column 5 reveals that even exposure to levels of PM2.5 20 $\mathrm{\mu g} / \mathrm{m}^{3}$ below the current 24-hour EPA air quality standards is detrimental to cognitive function, suggesting that there may be room for adjustments in the standards. For reference, $15 \mu \mathrm{g} / \mathrm{m}^{3}$ is about the ninety-fifth percentile of the distribution of particulates in our sample. Perhaps not surprisingly, column 6 shows that exposure to levels of PM2.5 above the current 24 -hour standards causes a large decline in cognitive performance. ${ }^{17}$

\footnotetext{
${ }^{17}$ In Appendix Figure A.5 we also check for nonlinearities in the relationship between PM2.5 and cognition using bins for different ranges of exposure.
} 


\section{B. Heterogeneous Impacts of Exposure to PM2.5 on Cognitive Function}

PM2.5 Impacts by Age. Figure 1, Panel A, depicts the causal effects by age group. All coefficients are jointly estimated using 2SLS in a version of Equation (2) with interactions between the indicator of high PM2.5 and the age groups reported in the figure. The pattern that emerges is that the adverse effects of exposure to PM2.5 are more pronounced at younger ages - below 50. The age distribution in our sample is displayed in Panel B, which shows a relatively small representation of individuals up to 40 years old, but a large representation of 50- and 60-year-olds. The mean user age in our sample is 48.7. Unlike the bulk of the literature highlighting detrimental effects of exposure to particle pollution on health outcomes among children and the elderly, our estimates reveal large impacts on the workingage population. To give a sense of the magnitude, take the estimated effect for individuals under 30 - exposure to levels of PM2.5 above $25 \mu \mathrm{g} / \mathrm{m}^{3}$ causes a reduction in standardized scores by 0.608 of a standard deviation. This effect is equivalent to the normal decay in cognitive function when comparing individuals under 30 to 45 -year-olds, as depicted by the diamond markers in Panel B. ${ }^{18}$

The effects of exposure to air pollution could be larger for younger individuals for a range of reasons. For example, according to well known theories of intelligence, as people age they begin to rely more on crystallized intelligence, that part of intelligence that comes from learned procedures and knowledge. ${ }^{19}$ If fluid intelligence - intelligence that is independent of learning - is more affected by short-term shocks to fine particulates, then we would expect to see younger and less experienced individuals are more affected. ${ }^{20}$

PM2.5 Impacts on Specific Cognitive Domains. Figure 2, Panel A, plots the estimated effects on seven cognitive domains - verbal, attention, flexibility, memory, math, speed, and

\footnotetext{
${ }^{18}$ Salthouse (2009) provides evidence that some aspects of age-related cognitive decline do begin in healthy educated adults when they are in their 20s and 30s. For a review of the literature on normal cognitive aging, see Harada, Natelson-Love and Triebel (2013).

${ }^{19}$ This theory is attributed to Raymond Cattell and Donald Hebb (Brown, 2016).

${ }^{20}$ This explanation is also consistent with the ability and learning results reported below.
} 
problem solving. All coefficients are jointly estimated using 2SLS in a version of Equation (2) with interactions between the indicator of high PM2.5 and the cognitive domains reported in the figure. Among these domains, the effects are strongest for memory, with exposure to PM2.5 above $25 \mu \mathrm{g} / \mathrm{m}^{3}$ estimated to reduce standardized scores by 0.598 of a standard deviation (95\% confidence interval: $[-1.147,-0.0489])$. There is also suggestive evidence that problem solving may also be substantially affected by particle pollution. The reduction in this cognitive domain due to high levels of PM2.5 is estimated to be 0.418 of a standard deviation (95\% CI: $[-1.517,0.681])$. Although we have a large number of observations associated with each domain, Lumosity games training memory and math are the least played, as reported by Panel B. ${ }^{21}$ The game training problem solving, however, is the most played in our setting.

To put the estimated impact of PM2.5 on memory into perspective, it is equivalent to the normal cognitive aging from the 30s to the 50s, as depicted by the diamond markers in Figure 1, Panel B. In the closest study to ours, Bedi et al. (2021) examine the impact of PM2.5 on five cognitive domains - simple attention, complex attention, arithmetic processing speed, working memory, and fluid reasoning - using a sample of 464 students from a university in Brazil, who engaged in 54 lab sessions over a 3-year period. They find evidence suggesting that one cognitive domain - fluid reasoning - may be more affected by high PM2.5 exposure. Fluid reasoning is the ability to think flexibly and problem solve. We find suggestive evidence of adverse effects on problem solving, but a near zero effect on flexibility. On the other hand, the effect we estimate on memory is more robust than other cognitive domains.

The adverse effect of PM2.5 on memory may have implications for workforce productivity. ${ }^{22}$ The Occupational Information Network $\left(\mathrm{O}^{*} \mathrm{NET}\right)$ database ranks over 870 occupations based on the importance of cognitive functions. ${ }^{23}$ Among the top twenty in terms of the

\footnotetext{
${ }^{21}$ Krebs and Luechinger (2021) focus their analysis on a mental arithmetic Lumosity game, and find evidence that exposure to nitrogen oxides (NOx) affects performance.

${ }^{22}$ Note, however, that lower cognitive performance caused by pollution may trigger adaptation responses by workers - such as mask-wearing - and firms - such as the installation of air filters (e.g., Adhvaryu, Kala and Anant, 2021).

${ }^{23}$ See details on the importance of cognition at onetonline.org/find/descriptor/browse/Abilities/1.A.1/ and onetonline.org/find/descriptor/browse/Skills/2.A/.
} 
importance of memory, there are actors, clergy members, physicians, nurses, inspectors, teachers, managers, engineers, and sales representatives. Therefore, it is not surprising that contemporaneous exposure to particulate matter decreases productivity among call center workers in China (Chang et al., 2019), but does not affect the manufacturing output of workers in the textile industry (He, Liu and Salvo, 2019). Our findings open a research avenue on the links between the impact of pollution on cognitive functions and labor productivity.

PM2.5 Impacts on Cognitive Function by Initial Ability. Figure 3, Panel A, plots the estimated effects of exposure to levels of PM2.5 above $25 \mu \mathrm{g} / \mathrm{m}^{3}$ on cognitive function by quintile of initial ability. All coefficients are jointly estimated using 2SLS in a version of Equation (2) with interactions between the indicator of high PM2.5 and quintiles of ability. Because memory appears to be the cognitive domain most affected by fine particulates, we measure initial ability by estimating the following equation for first play in the memory game:

$$
S_{i}=\phi \text { Wind }_{i}+X_{i}^{\prime} \Pi+\epsilon_{i}
$$

where $S_{i}$ represents standardized score for user $i$, and $W i n d_{i}$ the reduced-form equivalent of particle pollution. $X_{i}$ includes other meteorological controls and fixed effects for age, 3-digit ZIP code, and month-year. Our approximate measure of initial ability is the residualized score $\widehat{\epsilon_{i}}$, which nets out predictable patterns in the data. This measure has good predictive power for ability. Indeed, the pattern in Panel B reveals a strong positive association with educational attainment, which is knowingly correlated with innate ability (see, for example, discussion in Card, 2001). Panel B also shows that most users in our sample are college graduates.

The estimated effects in Figure 3, Panel A, indicate that low-ability individuals are more affected by exposure to high levels of PM2.5 than high-ability users. The difference between the point estimates for the second and fourth quintiles of -0.593 of a standard deviation is nontrivial: it is equivalent to the normal cognitive aging from the 30 s to the 50 s, as depicted by the diamond markers in Figure 1, Panel B. We are underpowered to draw strong 
conclusions, but the evidence from both panels, taken together, suggests that environmental insults might exacerbate the inequality in cognitive performance. This corroborates the pattern found by Ebenstein, Lavy and Roth (2016) for Israeli high-school students. They rank students based on an ex-ante measure of student quality reflecting performance in the full-year class and on a previously-taken SAT-equivalent test. When they split the sample by whether their measure of ability is above or below the median, the estimated detrimental impacts of exposure to ten additional units of PM2.5 are more than four times larger among those classified as low quality.

PM2.5 Impacts on Cognitive Function by Learning Stage. Figure 4, Panel A, displays the estimated effects of exposure to PM2.5 on cognition by practice in the games - fewer than five plays or more than five plays - which we are interpreting as different learning stages or experience. In fact, Panel B depicts a concave relationship between standardized scores and the number of plays, similar to the well-known experience-earnings profile in the labor market. The underlying histogram in the panel also reveals that most users play just a few times over our sample period, similar to the pattern of short job tenure for most workers in the labor force. ${ }^{24}$ All coefficients in Panel A are jointly estimated using 2SLS in a version of Equation (2) with interactions between the indicator of high PM2.5 and the learning-stage groups reported in the figure using only the sample of users who play a game at least 20 times.

The pattern emerging from Panel A is that exposure to relatively high levels of PM2.5 appears to affect cognitive performance primarily in the learning stage. Once users acquire experience, their performance is unaltered by fine particulates. ${ }^{25}$ In this case, the differencein-differences estimate of about 0.40 of a standard deviation - the difference between fewer and more than five plays for high PM2.5 minus the difference between fewer and more

\footnotetext{
${ }^{24}$ According to the Bureau of Labor Statistics, in January 2020 the median employee tenure was 4.3 years for men and 3.9 years for women (BLS, 2020).

${ }^{25}$ Krebs and Luechinger (2021) find the opposite pattern for the effects of exposure to NOx on the performance in mental arithmetic.
} 
than five plays for low PM2.5 - is marginally significant at conventional levels. That 0.40 difference-in-differences estimate roughly corresponds to the normal decay in cognitive function when comparing 30-year-olds to 40-year-olds, as depicted by the diamond markers in Figure 1, Panel B.

\section{Concluding Remarks}

This study has examined the impacts of exposure to fine particulate matter (PM2.5) on cognition, leveraging performances in brain games. We have taken advantage of detailed proprietary user-level data from Lumosity games over the period 2015-2017, covering seven cognitive domains across all stages of adult life. By instrumenting daily PM2.5 concentrations with changes in local wind direction à la Deryugina et al. $(2019),{ }^{26}$ we were able to identify the local average treatment effects of PM2.5 on cognitive functions, and assess the heterogeneity of those effects across multiple dimensions.

We highlight and discuss four main findings. First, the average impact of exposure to daily PM2.5 is substantial even at levels below the current 24-hour EPA ambient air quality standards of $35 \mu \mathrm{g} / \mathrm{m}^{3}$, and even at levels below the previous WHO air quality guideline value of $25 \mu \mathrm{g} / \mathrm{m}^{3}$. These results suggest that there may be additional benefits from reducing those thresholds. Second, among the seven cognitive domains we investigated, the effect on memory is the strongest. This has implications for the types of occupations most likely to suffer from high exposure to PM2.5, and might reconcile mixed results in the literature regarding occupations that were more or less affected by particulate matter. ${ }^{27}$ The memory result may also shed light on a mechanism behind the causal impact of sustained exposure to fine particulates on the probability of receiving a dementia diagnosis, as found by Bishop,

\footnotetext{
${ }^{26}$ As explained earlier, our instrument is an indicator variable for whether the daily local wind direction is at the direction associated with the maximum potential for the transport of pollutants from other locations to the area where the Lumosity user is located.

${ }^{27}$ For instance, exposure to particulate matter has been shown to decrease productivity among call center workers in China (Chang et al., 2019), but does not seem to affect the output of production workers in the textile industry (He, Liu and Salvo, 2019).
} 
Ketcham and Kuminoff (2018).

Third, unlike the bulk of evidence of adverse effects of PM2.5 on health outcomes concentrated among children and the elderly, our findings indicate that individuals under the age of 50 - the working-age population - may be the most affected by contemporaneous exposure to particle pollution. Furthermore, it seems that those learning new tasks may be more affected by short-term variation in PM2.5. Fourth, exposure to high levels of PM2.5 appears to exacerbate the inequality in cognitive performance. Low-ability individuals may be the most affected by fine particulates. This is suggestive evidence that investments in environmental quality are progressive, an important finding in the context of the recent rise in income inequality in the United States and abroad. 


\section{References}

Adhvaryu, Achyuta, Namrata Kala, and Nyshadham Anant. 2021. "Management and Shocks to Worker Productivity." Journal of Political Economy.

Ailshire, Jennifer A., and Eileen M. Crimmins. 2014. "Fine Particulate Matter Air Pollution and Cognitive Function Among Older US Adults." American Journal of Epidemiology, 180(4): 359-366.

Allen, J. L., C. Klocke, K. Morris-Schaffer, K. Conrad, M. Sobolewski, and D. A. Cory-Slechta. 2017. "Cognitive Effects of Air Pollution Exposures and Potential Mechanistic Underpinnings." Current Environmental Health Reports, 4(2): 180-191.

Anderson, Michael L. 2008. "Multiple Inference and Gender Differences in the Effects of Early Intervention: A Reevaluation of the Abecedarian, Perry Preschool, and Early Training Projects." Journal of the American Statistical Association, 103(484): 1481-1495.

Archsmith, James, Anthony Heyes, and Soodeh Saberian. 2018. "Air Quality and Error Quantity: Pollution and Performance in a High-Skilled, Quality-Focused Occupation." Journal of the Association of Environmental and Resource Economists, 5(4): 827863.

Austin, Wes, Gart Heutel, and Daniel Kreisman. 2019. "School Bus Emissions, Student Health and Academic Performance." Economics of Education Review, 70: 109-126.

Banzhaf, H. Spencer, and Randall P. Walsh. 2008. "Do People Vote with Their Feet? An Empirical Test of Tiebout." American Economic Review, 98(3): 843-863.

Banzhaf, H. Spencer, Lala Ma, and Christopher Timmins. 2019a. "Environmental Justice: Establishing Causal Relationships." Annual Review of Resource Economics, 11(1): 377-398.

Banzhaf, Spencer, Lala Ma, and Christopher Timmins. 2019b. "Environmental Justice: The Economics of Race, Place, and Pollution." Journal of Economic Perspectives, 33(1): 185-208.

Bedi, Arjun S., Marcos Y. Nakaguma, Brandon J. Restrepo, and Matthias Riege. 2021. "Particle Pollution and Cognition: Evidence from Sensitive Cognitive Tests in Brazil." Journal of the Association of Environmental and Resource Economists, 8(3): 443474.

Bharadwaj, Prashant, Matthew Gibson, Joshua Graff Zivin, and Christopher Neilson. 2017. "Gray Matters: Fetal Pollution Exposure and Human Capital Formation." Journal of the Association of Environmental and Resource Economists, 4(2): 505-542.

Bishop, Kelly C, Jonathan D Ketcham, and Nicolai V Kuminoff. 2018. "Hazed and confused: the effect of air pollution on dementia." NBER Working Paper \#24970.

BLS, Bureau of Labor Statistics, U.S. Department of Labor. 2020. "Employee Tenure in 2020." BLS News Release, Available at bls.gov/news.release/pdf/tenure.pdf, accessed on February 19, 2021.

Brown, Richard E. 2016. "Hebb and Cattell: The Genesis of the Theory of Fluid and Crystallized Intelligence." Frontiers in Human Neuroscience, 10: 606.

Cameron, A. Colin, Jonah B. Gelbach, and Douglas L. Miller. 2011. "Robust Inference With Multiway Clustering." Journal of Business 8 Economic Statistics, 29(2): 238- 
249.

Card, David. 2001. "Estimating the Return to Schooling: Progress on Some Persistent Econometric Problems." Econometrica, 69(5): 1127-1160.

Chang, Tom Y., Joshua Graff Zivin, Tal Gross, and Matthew Neidell. 2016. "Particulate Pollution and the Productivity of Pear Packers." American Economic Journal: Economic Policy, 8(3): 141-69.

Chang, Tom Y., Joshua Graff Zivin, Tal Gross, and Matthew Neidell. 2019. "The Effect of Pollution on Worker Productivity: Evidence from Call Center Workers in China." American Economic Journal: Applied Economics, 11(1): 151-72.

Chay, Kenneth Y., and Michael Greenstone. 2003. "The Impact of Air Pollution on Infant Mortality: Evidence from Geographic Variation in Pollution Shocks Induced by a Recession." Quarterly Journal of Economics, 118(3): 1121-1167.

Chay, Kenneth Y., and Michael Greenstone. 2005. "Does Air Quality Matter? Evidence from the Housing Market." Journal of Political Economy, 113(2): 376-424.

Chen, Yulong. 2019. "Early Exposure to Air Pollution and Cognitive Development Later in Life: Evidence from China." Mimeo.

Currie, Janet, and Matthew Neidell. 2005. "Air Pollution and Infant Health: What Can We Learn from California's Recent Experience?" Quarterly Journal of Economics, 120(3): 1003-1030.

Currie, Janet, and W. Reed Walker. 2011. "Traffic Congestion and Infant Health: Evidence from E-ZPass." American Economic Journal: Applied Economics, 3(1): 65-90.

Currie, Janet, Eric A. Hanushek, Megan E. Kahn, Matthew Neidell, and Steven G. Rivkin. 2009. "Does Pollution Increase School Absences?" Review of Economics and Statistics, 91(4): 682-94.

Currie, Janet, Joshua Graff Zivin, Jamie Mullins, and Matthew Neidell. 2014. "What Do We Know About Short- and Long-Term Effects of Early-Life Exposure to Pollution?" Annual Review of Resource Economics, 6(1): 217-247.

Currie, Janet, Lucas W. Davis, Michael Greenstone, and W. Reed Walker. 2015. "Environmental Health Risks and Housing Values: Evidence from 1,600 Toxic Plant Openings and Closings." American Economic Review, 105(2): 678-709.

Davis, David A., Garnik Akopian, John P. Walsh, Constantinos Sioutas, Todd E. Morgan, and Caleb E. Finch. 2013. "Urban air pollutants reduce synaptic function of CA1 neurons via an NMDA/N pathway in vitro." Journal of Neurochemistry, 127(4): 509519.

Deryugina, Tatyana, Garth Heutel, Nolan H. Miller, David Molitor, and Julian Reif. 2019. "The Mortality and Medical Costs of Air Pollution: Evidence from Changes in Wind Direction." American Economic Review, 109(12): 4178-4219.

Deschenes, Olivier, Michael Greenstone, and Joseph S. Shapiro. 2017. "Defensive Investments and the Demand for Air Quality: Evidence from the NOx Budget Program." American Economic Review, 107(10): 2958-89.

Diamond, Adele, and Daphne S. Ling. 2020. "Review of the Evidence on, and Fundamental Questions About, Efforts to Improve Executive Functions, Including Working 
Memory." In Cognitive and Working Memory Training: Perspectives From Psychology, Neuroscience, and Human Development., ed. Jared M. Novick, Michael F. Bunting, Michael R. Dougherty and Randall W. Engle. Oxford, UK:Oxford University Press.

Ebenstein, Avraham, Victor Lavy, and Sefi Roth. 2016. "The Long-Run Economic Consequences of High-Stakes Examinations: Evidence from Transitory Variation in Pollution." American Economic Journal: Applied Economics, 8(4): 36-65.

Fu, Shihe, V. Brian Viard, and Peng Zhang. 2017. "Air Quality and Manufacturing Firm Productivity: Comprehensive Evidence from China." Mimeo.

Gilraine, Michael. 2020. "Air Filters, Pollution, and Student Achievement." Mimeo.

Graff Zivin, Joshua, and Matthew Neidell. 2012. "The Impact of Pollution on Worker Productivity." American Economic Review, 102(7): 3652-3673.

Graff Zivin, Joshua, and Matthew Neidell. 2013. "Environment, Health, and Human Capital." Journal of Economic Literature, 51(3): 689-730.

Ham, John C., Jacqueline S. Zweig, and Edward Avol. 2014. "Pollution, Test Scores and Distribution of Academic Achievement: Evidence from California Schools 2002-2008." Mimeo.

Hanna, Rema, and Paulina Oliva. 2015. "The Effect of Pollution on Labor Supply: Evidence from a Natural Experiment in Mexico City." Journal of Public Economics, 122: 6879 .

Harada, Caroline N., Marissa C. Natelson-Love, and Kristen L. Triebel. 2013. "Normal Cognitive Aging." Clinics in Geriatric Medicine, 29(4): 737-752.

Heblich, Stephan, Alex Trew, and Yanos Zylberberg. 2021. "East-Side Story: Historical Pollution and Persistent Neighborhood Sorting." Journal of Political Economy, 129(5): 1508-1552.

Heissel, Jennifer A., Claudia L. Persico, and David Simon. Forthcoming. "Does Pollution Drive Achievement? The Effect of Traffic Pollution on Academic Performance." Journal of Human Resources.

Heissel, Jennifer A., Claudia Persico, and David Simon. 2020. "Does Pollution Drive Achievement? The Effect of Traffic Pollution on Academic Performance." Journal of Human Resources.

He, Jiaxiu, Haoming Liu, and Alberto Salvo. 2019. "Severe Air Pollution and Labor Productivity: Evidence from Industrial Towns in China." American Economic Journal: Applied Economics, 11(1): 173-201.

Heyes, Anthony, Matthew Neidell, and Soodeh Saberian. 2016. "The Effect of Air Pollution on Investor Behavior: Evidence from the S\&P 500." NBER Working Paper \#22753.

Hsiang, Solomon M., Paulina Oliva, and Reed Walker. 2019. "The Distribution of Environmental Damages." Review of Environmental Economics and Policy, 13(1): 83-103.

Huang, Jiekun, Nianhang Xu, and Honghai Yu. 2020. "Pollution and Performance: Do Investors Make Worse Trades on Hazy Days?" Management Science.

Kilian, Jason, and Masashi Kitazawa. 2018. "The emerging risk of exposure to air pollution on cognitive decline and Alzheimer's disease - Evidence from epidemiological 
and animal studies." Biomedical Journal, 41(3): 141-162.

Krebs, Benjamin, and Simon Luechinger. 2021. "Air Pollution, Cognitive Performance, and the Role of Task Proficiency." SSRN Working Paper - October 2021.

Marcotte, Dave E. 2017. "Something in the air? Air quality and children's educational outcomes." Economics of Education Review, 56: 141-151.

Meyer, Steffen, and Michaela Pagel. 2017. "Fresh Air Eases Work - The Effect of Air Quality on Individual Investor Activity." NBER Working Paper \#24048.

Miller, Sebastian, and Mauricio Vela. 2013. "The Effects of Air Pollution on Educational Outcomes: Evidence from Chile." IDB Working Paper No. IDB-WP-468.

Moretti, Enrico, and Matthew Neidell. 2011. "Pollution, Health, and Avoidance Behavior: Evidence from the Ports of Los Angeles." Journal of Human Resources, 46(1): 154-75.

Paul, Kimberly C., Mary Haan, Elizabeth Rose Mayeda, and Beate R. Ritz. 2019. "Ambient Air Pollution, Noise, and Late-Life Cognitive Decline and Dementia Risk." Annual Review of Public Health, 40(1): 203-220.

Persico, Claudia L., and Joanna Venator. Forthcoming. "The Effects of Local Industrial Pollution on Students and Schools." Journal of Human Resources.

Roth, Sefi J. 2020. "The Effect of Indoor Air Pollution on Cognitive Performance: Evidence from the UK." Mimeo.

Salthouse, Timothy A. 2009. "When does age-related cognitive decline begin?" Neurobiology of Aging, 30(4): 507-514.

Sanders, Nicholas J. 2012. "What Doesn't Kill You Makes You Weaker: Prenatal Pollution Exposure and Educational Outcomes." Journal of Human Resources, 47(3): 826-850.

Sanderson, Eleanor, and Frank Windmeijer. 2016. "A Weak Instrument F-test in Linear IV Models with Multiple Endogenous Variables." Journal of Econometrics, 190(2): 212-221.

Schikowski, Tamara, and Hicran Altuğ. 2020. "The role of air pollution in cognitive impairment and decline." Neurochemistry International, 136: 104708.

Schlenker, Wolfram, and W. Reed Walker. 2016. "Airports, Air Pollution, and Contemporaneous Health." Review of Economic Studies, 83(2): 768-809.

Shehab, MA, and FD Pope. 2019. "Effects of short-term exposure to particulate matter air pollution on cognitive performance." Scientific reports, 9(1): 1-10.

Simons, Daniel J., Walter R. Boot, Neil Charness, Susan E. Gathercole, Christopher F. Chabris, David Z. Hambrick, and Elizabeth A. L. Stine-Morrow. 2016. "Do "Brain-Training" Programs Work?" Psychological Science in the Public Interest, 17(3): 103-186.

Smid, Claire R., Julia Karbach, and Nikolaus Steinbeis. 2020. "Toward a Science of Effective Cognitive Training." Current Directions in Psychological Science, 29(6): 531-537.

Stafford, Tess M. 2015. "Indoor Air Quality and Academic Performance." Journal of Environmental Economics and Management, 70: 34-50.

Staiger, Douglas, and James H. Stock. 1997. "Instrumental Variables Regression with Weak Instruments." Econometrica, 65(3): 557-586.

Wang, Yan, Lilin Xiong, and Meng Tang. 2017. "Toxicity of inhaled particulate mat- 
ter on the central nervous system: neuroinflammation, neuropsychological effects and neurodegenerative disease." Journal of Applied Toxicology, 37(6): 644-667.

Younan, Diana, Andrew J. Petkus, Keith F. Widaman, Xinhui Wang, Ramon Casanova, Mark A. Espeland, Margaret Gatz, Victor W. Henderson, JoAnn E. Manson, Stephen R. Rapp, Bonnie C. Sachs, Marc L. Serre, Sarah A. Gaussoin, Ryan Barnard, Santiago Saldana, William Vizuete, Daniel P. Beavers, Joel A. Salinas, Helena C. Chui, Susan M. Resnick, Sally A. Shumaker, and Jiu-Chiuan Chen. 2019. "Particulate matter and episodic memory decline mediated by early neuroanatomic biomarkers of Alzheimer's disease." Brain, 143(1): 289-302.

Zhang, Xin, Xi Chen, and Xiaobo Zhang. 2018. "The impact of exposure to air pollution on cognitive performance." Proceedings of the National Academy of Sciences, 115(37): 9193-9197. 
Figure 1: IV PM2.5 Impacts on Cognitive Function by Age

Panel A. IV Estimated Effects

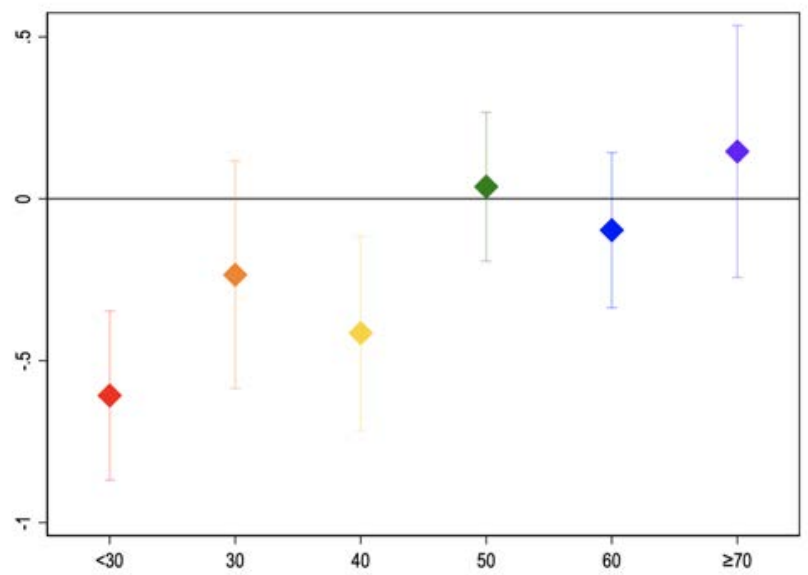

Panel B. Age Distribution

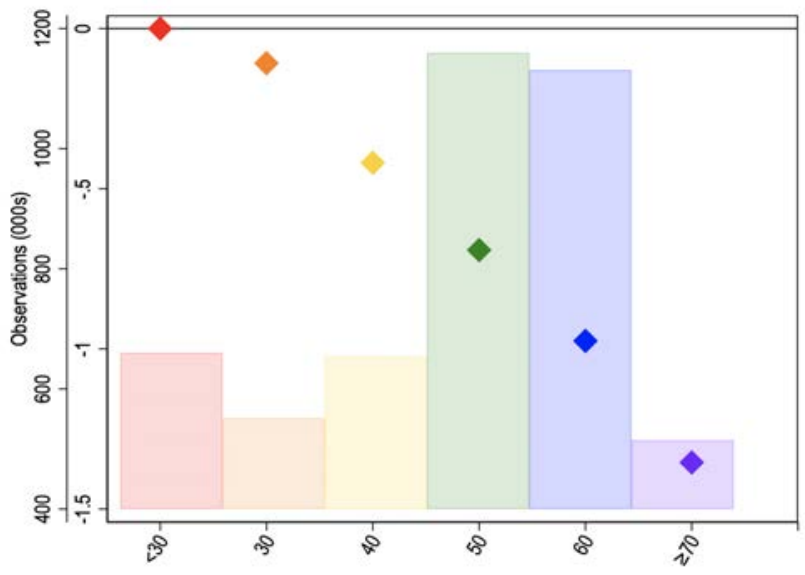

Notes: This figure displays the IV estimated impacts of exposure to PM2.5 above $25 \mu \mathrm{g} / \mathrm{m}^{3}$ by age, and descriptive statistics on the age distribution in our sample. In Panel A, the plotted coefficients are jointly estimated using 2SLS in a version of Equation (2) with interactions between the indicator of high PM2.5 and age groups. The instruments for these interactions are interactions of our original instrument with the bins for age groups. The vertical bars around the coefficients are $95 \%$ confidence intervals. The estimates are also reported in Appendix Table A.4, including the conditional first-stage F statistics. Robustness checks are presented in Appendix Figure A.6. Heterogeneity analysis by age and gender is presented in Appendix Figure A.7. In Panel B, the bars depict the number of observations in each age range, and the markers show the change in average standardized scores for an age group relative to users under 30 . Learning curves associated with each age group are presented in Appendix Figure A.8. 
Figure 2: IV PM2.5 Impacts on Specific Cognitive Domains

Panel A. IV Estimated Effects

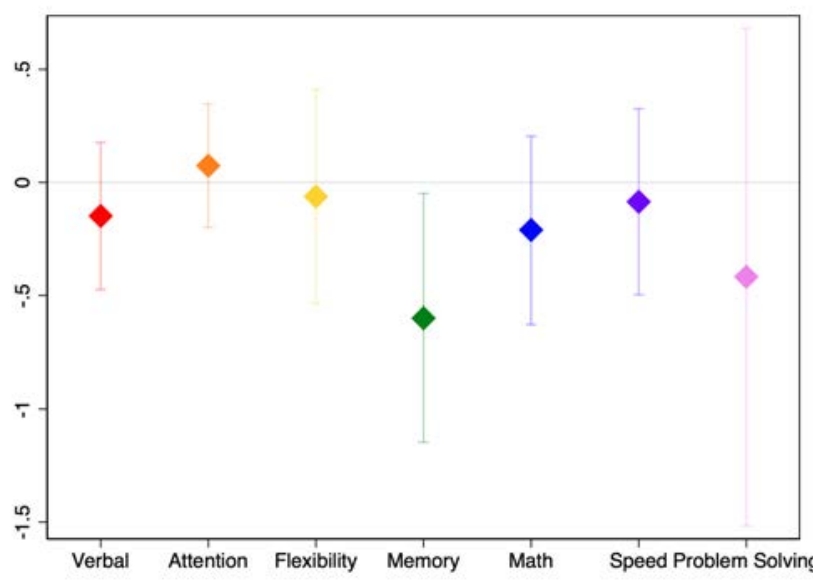

Panel B. Game Distribution

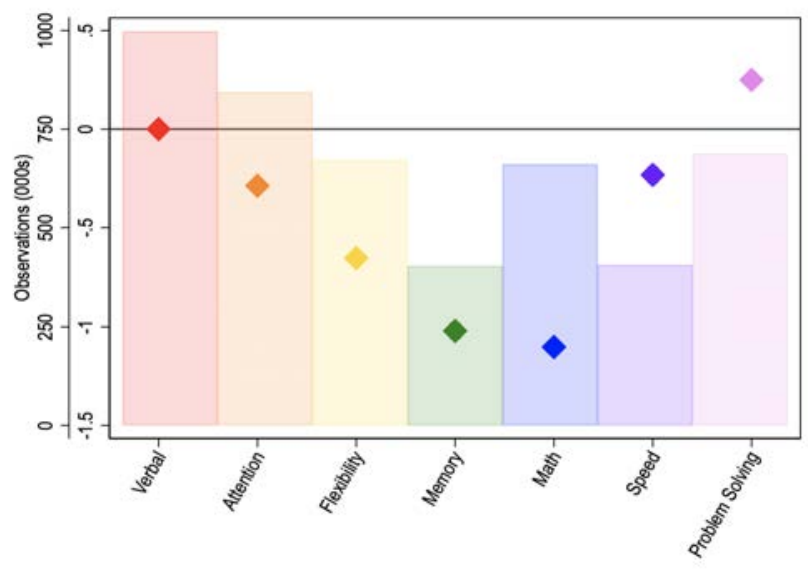

Notes: This figure displays the IV estimated impacts of exposure to PM2.5 above $25 \mu \mathrm{g} / \mathrm{m}^{3}$ by cognitive domain, and descriptive statistics on the distribution of observations across games in our sample. In Panel A, the plotted coefficients are jointly estimated using 2SLS in a version of Equation (2) with interactions between the indicator of high PM2.5 and cognitive domains. The instruments for these interactions are interactions of our original instrument with indicators for cognitive domains. The vertical bars around the coefficients are $95 \%$ confidence intervals. The estimates are also reported in Appendix Table A.5, including the conditional first-stage F statistics. A robustness check is presented in Appendix Figure A.9. In Panel B, the bars depict the number of observations in each game, and the markers show the change in the number of times the game is played by an individual relative to the verbal game. 
Figure 3: IV PM2.5 Impacts on Cognitive Function by Initial Ability

\section{Panel A. IV Estimated Effects}

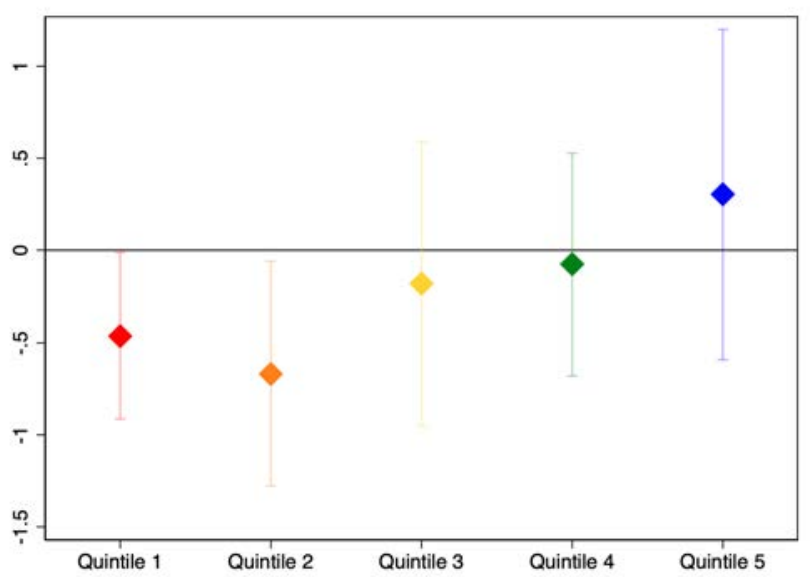

Panel B. Initial Ability and Education

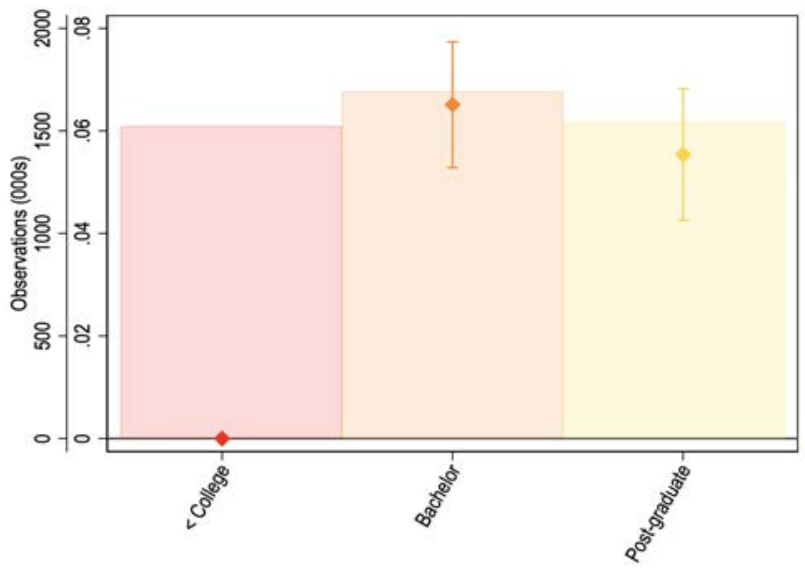

Notes: This figure displays the IV estimated impacts of exposure to PM2.5 above $25 \mu \mathrm{g} / \mathrm{m}^{3}$ by initial ability, and descriptive statistics on ability and educational attainment in our sample. In Panel A, the plotted coefficients are jointly estimated using 2SLS in a version of Equation (2) with interactions between the indicator of high PM2.5 and quintiles of initial ability. Our measure of ability is based on the first play in the memory game. In practice, it is the residualized score from Equation (4). The instruments for those interactions are interactions of our original instrument with indicators for quintiles of initial ability. The vertical bars around the coefficients are $95 \%$ confidence intervals. The estimates are also reported in Appendix Table A.6, including the conditional first-stage F statistics. Robustness checks are presented in Appendix Figure A.10, and analysis using education groups as an alternative for quintiles of initial ability is presented in Appendix Figure A.11. In Panel B, the bars depict the number of observations in each education group, and the markers show the change in average initial ability for an education group relative to the category less than college degree. 
Figure 4: IV PM2.5 Impacts on Specific Cognitive Function by Learning Stage

Panel A. IV Estimated Effects

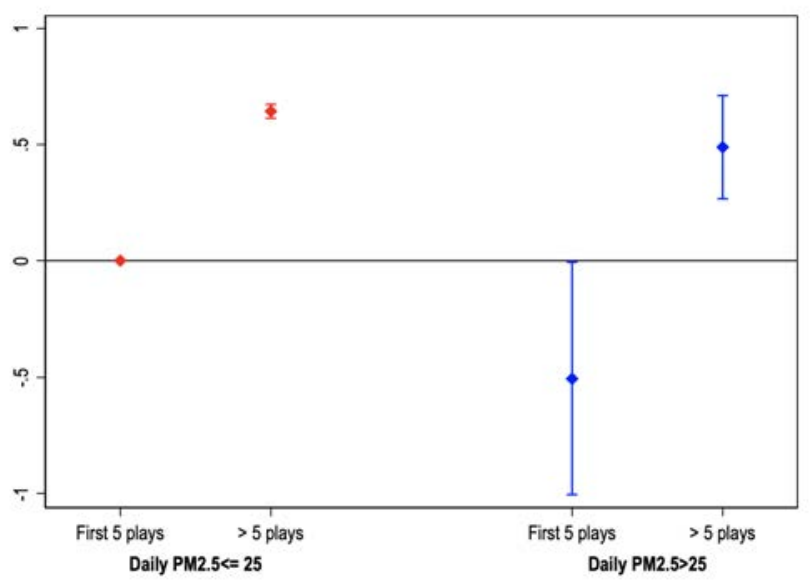

Panel B. Number of Plays and Learning

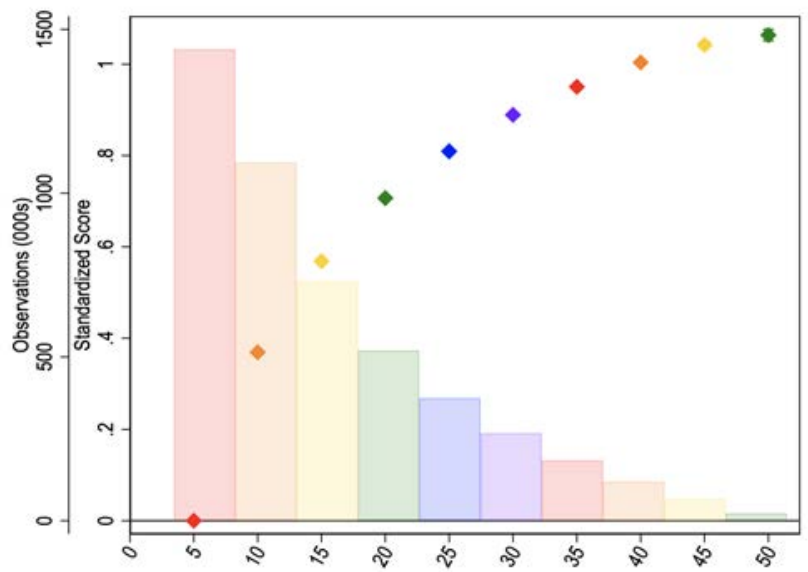

Notes: This figure displays the IV estimated impacts of exposure to PM2.5 above $25 \mu \mathrm{g} / \mathrm{m}^{3}$ by experience playing Lumosity games, and descriptive statistics on the distribution of number of game plays and learning in our sample. In Panel A, the plotted coefficients are jointly estimated using 2SLS in a version of Equation (2) with interactions between the indicator of high PM2.5 and two categories of number of plays - fewer or more than five plays - for the sample of users playing at least 20 times. The instruments for these interactions are interactions of our original instrument with indicators for categories of number of plays. The vertical bars around the coefficients are $95 \%$ confidence intervals. The estimates are also reported in Appendix Table A.7, including the conditional first-stage F statistics. A robustness check is presented in Appendix Figure A.12. In Panel B, the bars depict the number of observations for each binned number of plays, and the markers show the average standardized score for each binned number of plays relative to the first 5 plays bin. 
Table 1: Impacts of Exposure to PM2.5 on Cognition - Average Effects and Robustness

\begin{tabular}{|c|c|c|c|c|c|c|}
\hline \multicolumn{7}{|c|}{ Panel A. Average OLS Estimates (Columns 1-2) and IV Estimates (Columns 3-6) } \\
\hline Dep. Var.: Std. Score & $(1)$ & $(2)$ & $(3)$ & $(4)$ & $(5)^{\#}$ & $(6)^{\#}$ \\
\hline Daily PM2.5 $\left(\mu g / m^{3}\right)$ & $\begin{array}{c}-0.000520^{* *} \\
(0.000178)\end{array}$ & & $\begin{array}{c}-0.00486^{* *} \\
(0.00207)\end{array}$ & & $\begin{array}{l}-0.154^{* *} \\
(0.0600)\end{array}$ & \\
\hline $\mathbf{1}[$ Daily PM2.5 >25] & & $\begin{array}{l}-0.0197^{* *} \\
(0.00632)\end{array}$ & & $\begin{array}{c}-0.183^{* *} \\
(0.0803)\end{array}$ & & $\begin{array}{c}-5.809^{* *} \\
(2.316)\end{array}$ \\
\hline User FE & $\mathrm{Y}$ & $\mathrm{Y}$ & $\mathrm{Y}$ & $\mathrm{Y}$ & $\mathrm{Y}$ & $\mathrm{Y}$ \\
\hline Month by Year FE & Y & $\mathrm{Y}$ & Y & $\mathrm{Y}$ & $\mathrm{Y}$ & $\mathrm{Y}$ \\
\hline Meteorological controls & Y & $\mathrm{Y}$ & Y & $\mathrm{Y}$ & $\mathrm{Y}$ & Y \\
\hline Observations & $4,667,636$ & $4,667,636$ & $4,667,636$ & $4,667,636$ & $4,667,636$ & $4,667,636$ \\
\hline First-stage F & & & 40.86 & 33.24 & 40.86 & 33.24 \\
\hline Hausman test (p-value) & & & 0.094 & 0.086 & 0.049 & 0.043 \\
\hline Panel B. IV Estimates for & Alternative & pecifications & s, Sample, a & d Variable & Definitions & \\
\hline Dep. Var.: Std. Score & (1) & $(2)$ & (3) & (4) & $(5)$ & (6) \\
\hline 1[Daily PM2.5 >25] & $\begin{array}{l}-0.197^{* *} \\
(0.0943)\end{array}$ & $\begin{array}{l}-0.176^{* *} \\
(0.0760)\end{array}$ & $\begin{array}{l}-0.211^{* *} \\
(0.0891)\end{array}$ & $\begin{array}{c}-0.227^{* *} \\
(0.110)\end{array}$ & & \\
\hline $\mathbf{1}[$ Daily PM2.5 > 25] $(t-1)$ & & & $\begin{array}{l}0.0567 \\
(0.111)\end{array}$ & & & \\
\hline $\mathbf{1}[$ Daily PM2.5 $>25](t+1)$ & & & $\begin{array}{c}0.00680 \\
(0.103)\end{array}$ & & & \\
\hline $\mathbf{1}[$ Daily PM2.5 >15] & & & & & $\begin{array}{l}-0.150^{*} \\
(0.0760)\end{array}$ & \\
\hline $\mathbf{1}[$ Daily PM2.5 >35] & & & & & & $\begin{array}{c}-0.654^{* *} \\
(0.294)\end{array}$ \\
\hline User FE & & $\mathrm{Y}$ & $\mathrm{Y}$ & $\mathrm{Y}$ & $\mathrm{Y}$ & $\mathrm{Y}$ \\
\hline User by Hour-of-day FE & $\mathrm{Y}$ & & & & & \\
\hline Game FE & $\mathrm{Y}$ & & & & & \\
\hline Month by Year FE & $\mathrm{Y}$ & $\mathrm{Y}$ & $\mathrm{Y}$ & $\mathrm{Y}$ & $\mathrm{Y}$ & Y \\
\hline Day-of-week FE & $\mathrm{Y}$ & $\mathrm{Y}$ & & & & \\
\hline Zip2 by Month-of-year FE & & $\mathrm{Y}$ & & & & \\
\hline Meteorological controls & $\mathrm{Y}$ & $\mathrm{Y}$ & Y & $\mathrm{Y}$ & $\mathrm{Y}$ & $\mathrm{Y}$ \\
\hline Sample Restriction & & & & $\mathrm{Y}$ & $\mathrm{Y}$ & \\
\hline Observations & $4,382,220$ & $4,667,636$ & $4,635,654$ & $4,659,194$ & $4,659,194$ & $4,667,636$ \\
\hline First-stage F & 36.46 & 32.63 & 6.349 & 36.32 & 26.42 & 17.45 \\
\hline
\end{tabular}

Notes: This table reports the impacts of exposure to PM2.5 on cognitive function, as measured by standardized scores in Lumosity games - mean zero and standard deviation one. \# in the last two columns of Panel A indicates that an alternative dependent variable has been used: the percentile of a score in the distribution of scores adjusted to match the characteristics of the U.S. population. IV estimates arise from instrumenting daily PM2.5 with an indicator variable for whether the daily local wind direction is at the direction associated with the maximum potential for the transport of pollutants from other locations to a 3-digit ZIP code area where the Lumosity users are located. The first-stage F statistic is the Kleibergen-Paap rk Wald F statistic associated with the excluded instrument in the first stage. The null hypothesis for the Hausman test is that the difference between the OLS and IV estimates is not systematic. Meteorological controls include wind speed, precipitation and bins of daily maximum temperature. "Zip2" at the bottom of Panel B represents a 2-digit ZIP code region, an aggregation of 3-digit ZIP code areas, which are the smallest geographical units identified for the individuals in our data. The "sample restriction" also at the bottom of Panel B refers to the removal of outlier observations for PM2.5 - those above $35 \mu \mathrm{g} / \mathrm{m}^{3}$, the current 24-hour EPA standards for PM2.5. Standard errors double-clustered at the user and month-by-year levels are reported in parentheses. *** denotes statistical significance at the $1 \%$ level, ${ }^{* *}$ at the $5 \%$ level, and ${ }^{*}$ at the $10 \%$ level. 
Online Appendix (Not For Publication)

\section{"Air Pollution and Adult Cognition: Evidence from Brain Training"}

Andrea La Nauze and Edson Severnini*

*La Nauze: University of Queensland, a.lanauze@uq.edu.au. Severnini: Carnegie Mellon University and IZA, edsons@andrew.cmu.edu. 


\section{Appendix A: Figures and Tables}

Figure A.1: The 3-Digit ZIP Code Areas in the United States

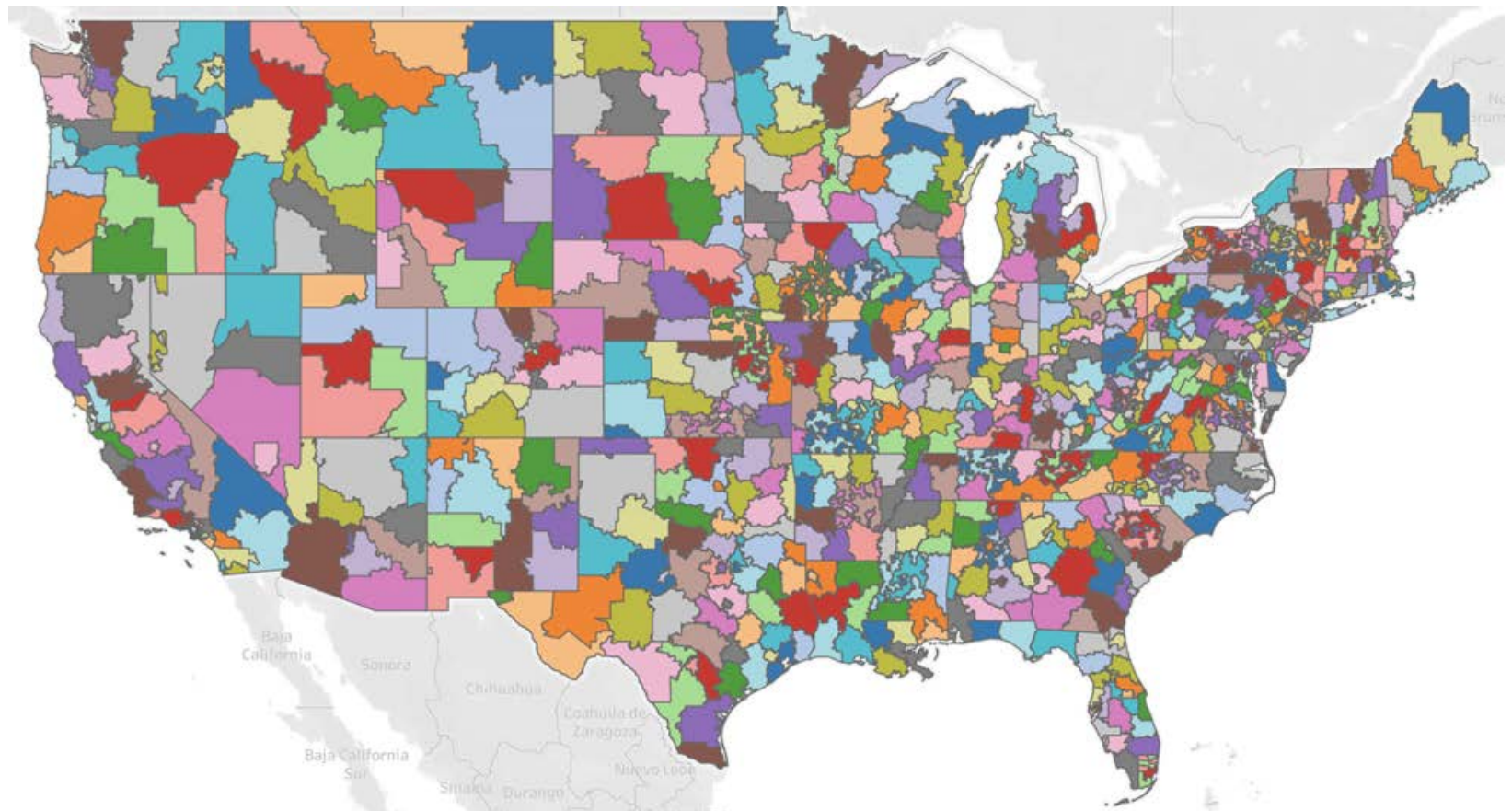

Notes: This figure displays the 3-digit ZIP code areas in the continental United States. This is the smallest geographical unit identified in the Lumosity brain training data, which is derived from a user's IP address. For reference, there are currently 41,692 5-digit ZIP codes in the country, 929 3-digit ZIP code areas, and 99 2-digit ZIP code regions. Source: https://public.tableau.com/views/ZIP3Map/ZIP3NationalMap?. 
Figure A.2: Distribution of Lumosity Users

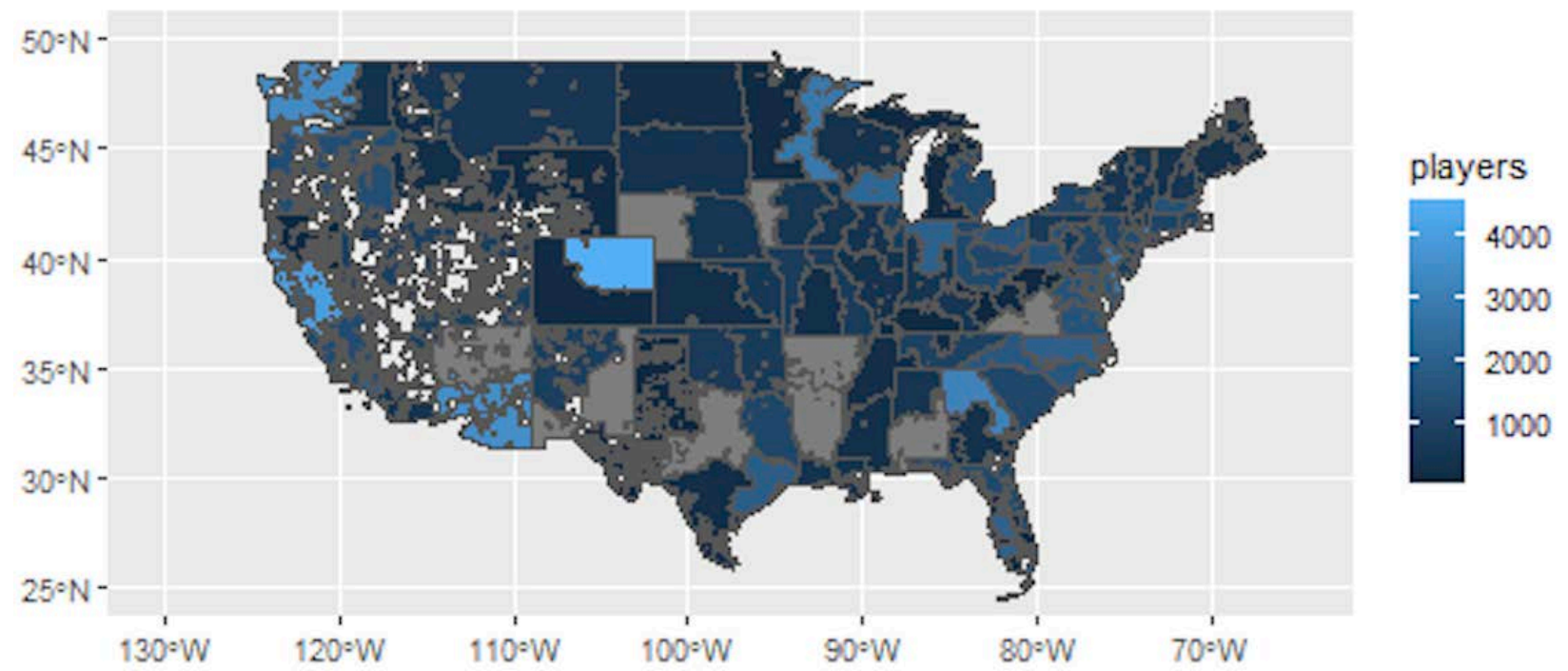

Notes: This figure maps the distribution of users of Lumosity brain games in our sample over the period 20152017. Gray indicates no users. Those individuals are scattered around the nation, with heavy concentrations in the West coast, where Lumos Labs, the owner of Lumosity, are headquartered (San Francisco, CA). 
Figure A.3: Daily PM2.5 Variation in Our Sample

Panel A. Entire Distribution

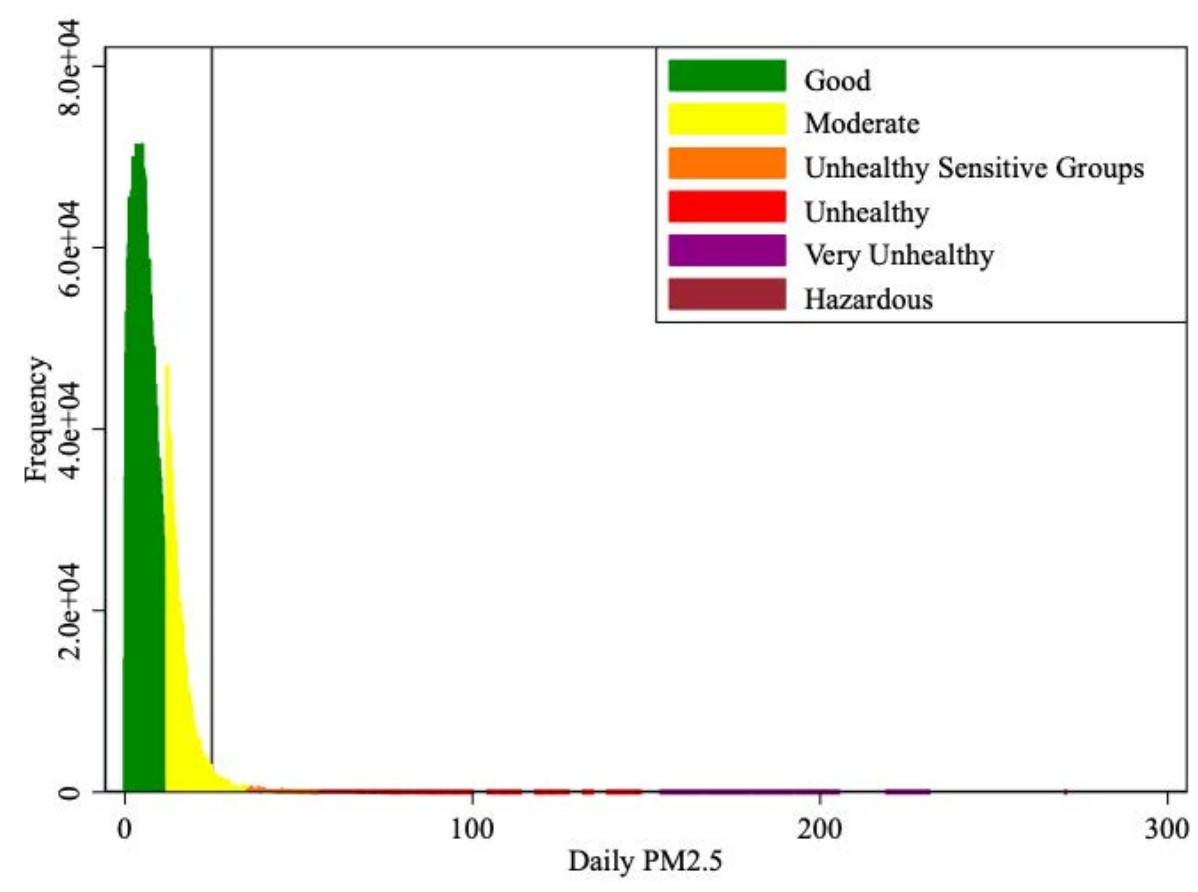

Panel B. Variation Above $25 \mu \mathrm{g} / \mathrm{m}^{3}$

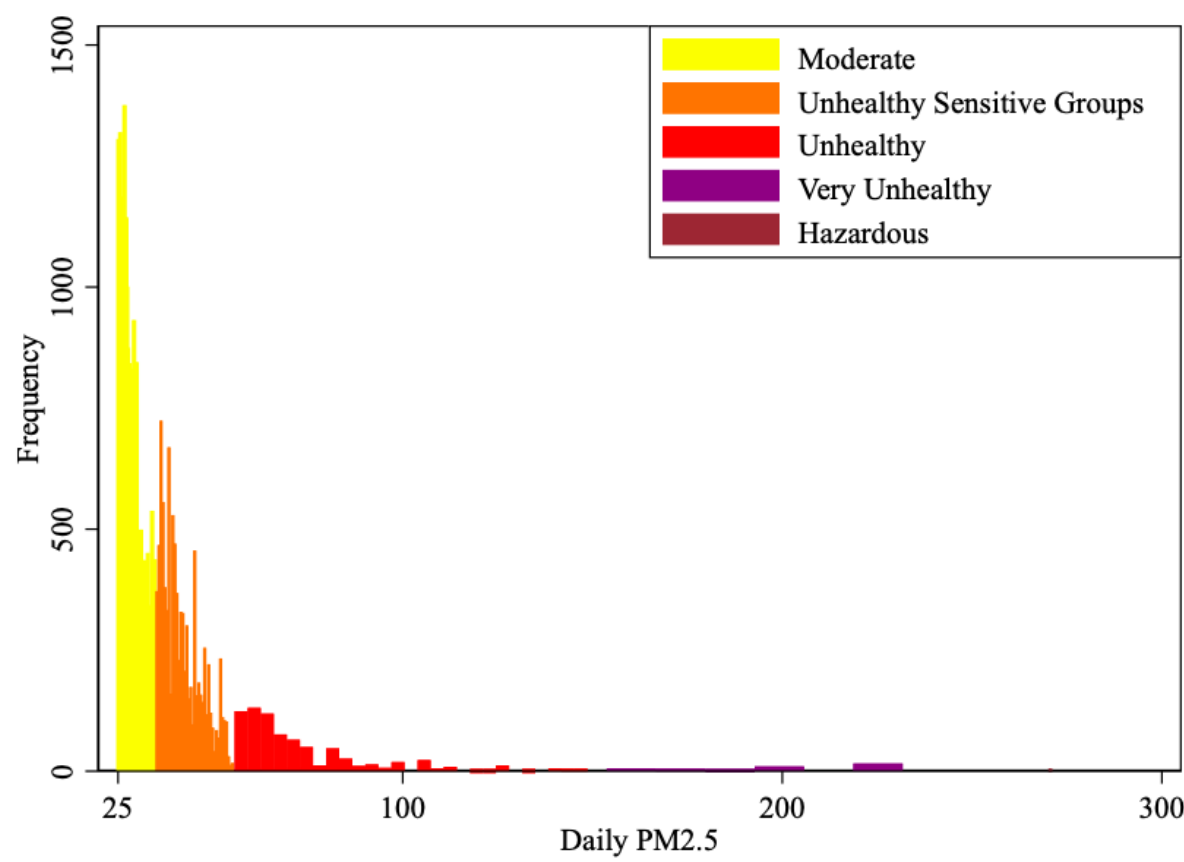

Notes: This figure displays the distribution of daily PM2.5 in our sample. The levels of PM2.5 are colorcoded according to the colors used by EPA to provide air quality information to the public via the air quality index (AQI). Panel A shows the entire distribution. The median daily PM2.5 in our sample $4.48 \mu \mathrm{g} / \mathrm{m}^{3}$, the mean is $5.61 \mu \mathrm{g} / \mathrm{m}^{3}$, and the standard deviation $5.02 \mu \mathrm{g} / \mathrm{m}^{3}$. Panel B zooms in over the portion of the distribution above the threshold used in our main analysis $-25 \mu \mathrm{g} / \mathrm{m}^{3}$. This threshold is the World Health Organization (WHO) air quality guideline value for 24-hour exposure to PM2.5, but still $10 \mu \mathrm{g} / \mathrm{m}^{3}$ below the U.S. National Ambient Air Quality Standards (NAAQS) for PM2.5 over 24 hours. 


\section{Figure A.4: IV PM2.5 Impacts on Number and Composition of Players}

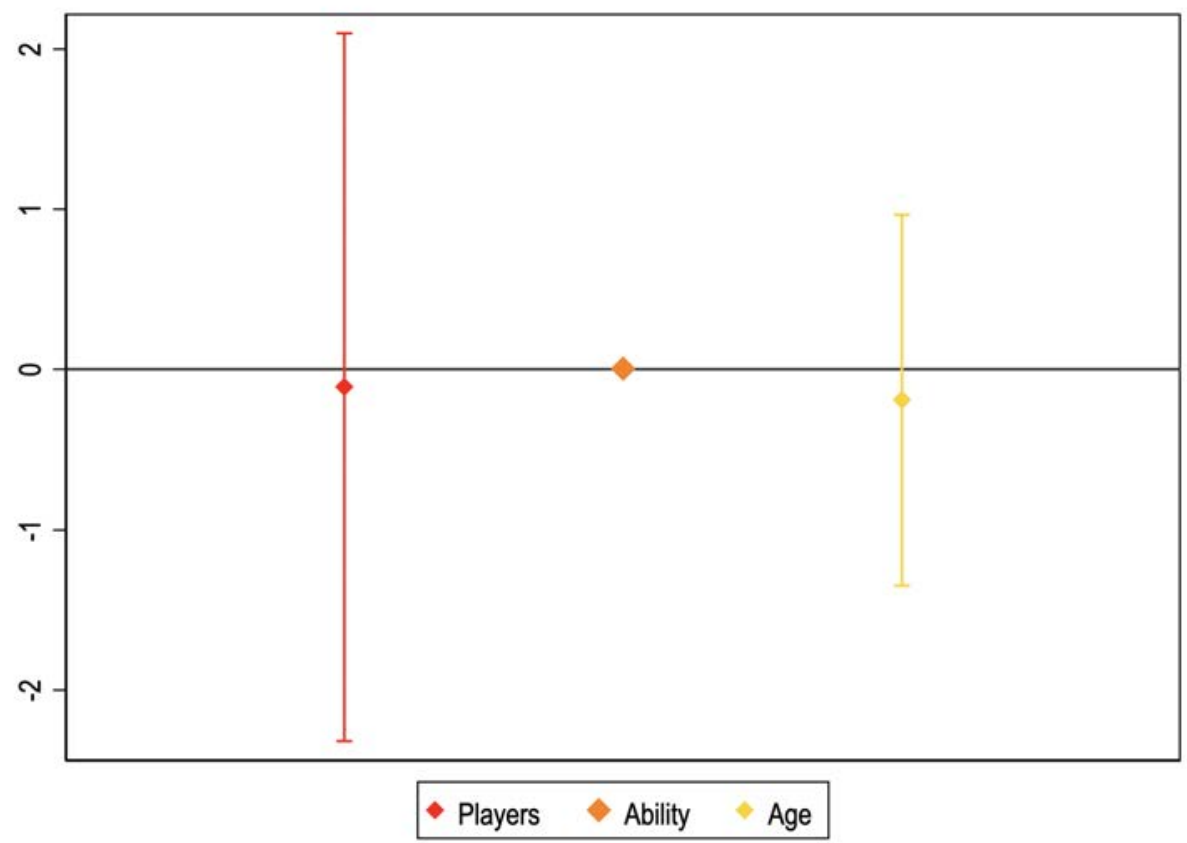

Notes: This figure displays the IV estimated impacts of exposure to PM2.5 above $25 \mu \mathrm{g} / \mathrm{m}^{3}$ on the number and composition of players. The plotted coefficients are estimated via 2SLS in separate regressions of each outcome on an indicator for PM2.5 > 25 and the same control variables as in Equation (2) - wind speed, precipitation and bins of daily maximum temperature. Our measure of ability is based on the first play in the memory game. In practice, it is the residualized score from Equation (4). The vertical bars around the coefficients are $95 \%$ confidence intervals. 
Figure A.5: IV Nonlinear Impacts of PM2.5 on Cognitive Function

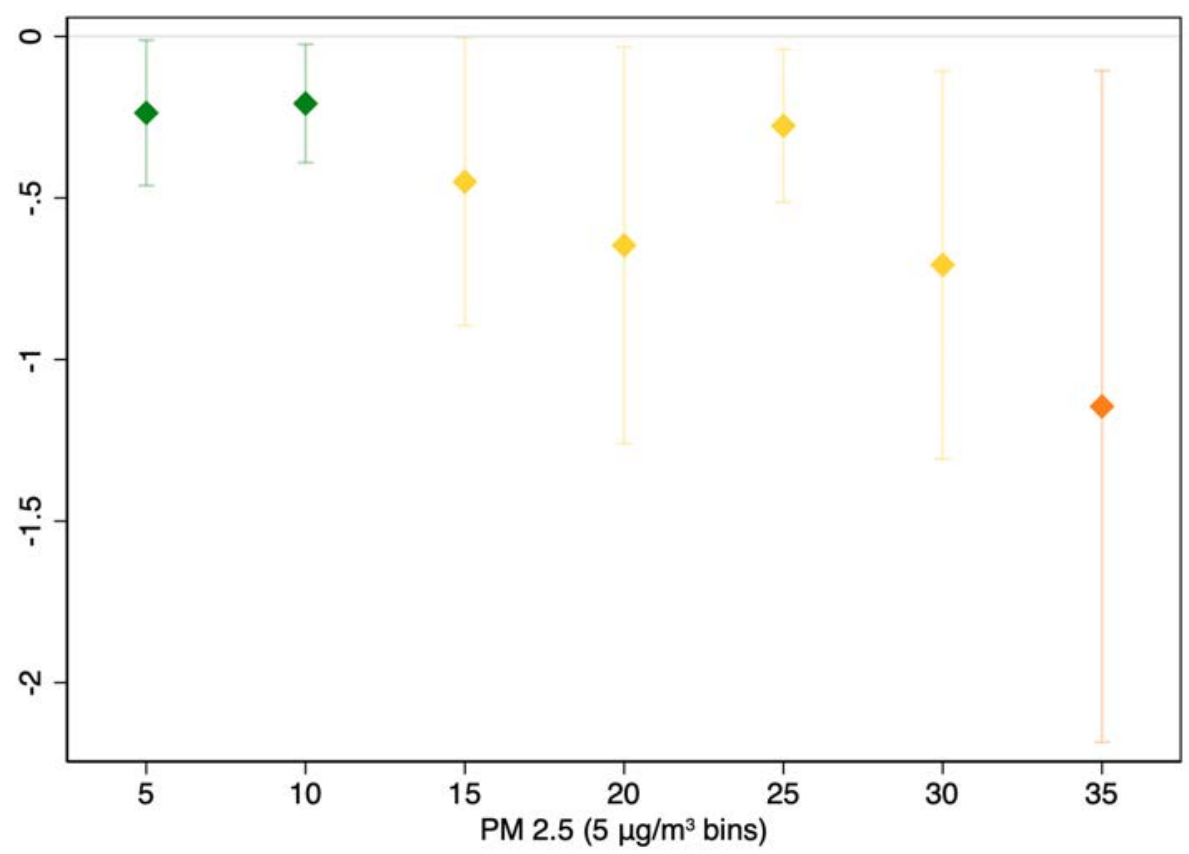

Notes: This figure displays the IV estimated nonlinear impacts of exposure to PM2.5 relative to levels below $5 \mu \mathrm{g} / \mathrm{m}^{3}$. The plotted coefficients are separately estimated using 2SLS in a version of Equation (2) with each of the seven $5 \mu \mathrm{g} / \mathrm{m}^{3}$-bin indicators for PM2.5. For each estimate the sample is restricted to observations with $P M 2.5<5 \mu \mathrm{g} / \mathrm{m}^{3}$ and observations with high PM2.5 as defined by the bin indicator. The last bin is for PM2.5 between $35 \mu \mathrm{g} / \mathrm{m}^{3}$ and $40 \mu \mathrm{g} / \mathrm{m}^{3}$. The colors of the coefficients in this figure are associated with the color code for the AQI, as explained in A.3). Because the distribution of particulates is highly right-skewed, with the median slightly below $5 \mu \mathrm{g} / \mathrm{m}^{3}$ (see Figure A.3), in this figure the vertical bars around the coefficients are $90 \%$ confidence intervals. 
Figure A.6: IV PM2.5 Impacts on Cognitive Function by Age - Robustness Checks

Panel A. Controlling for Game FE

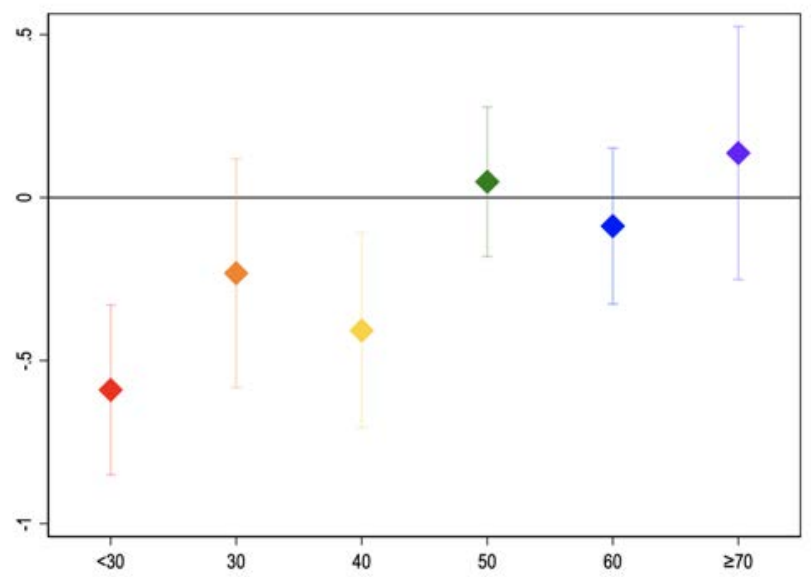

Panel B. Controlling for >5 Plays Dummy

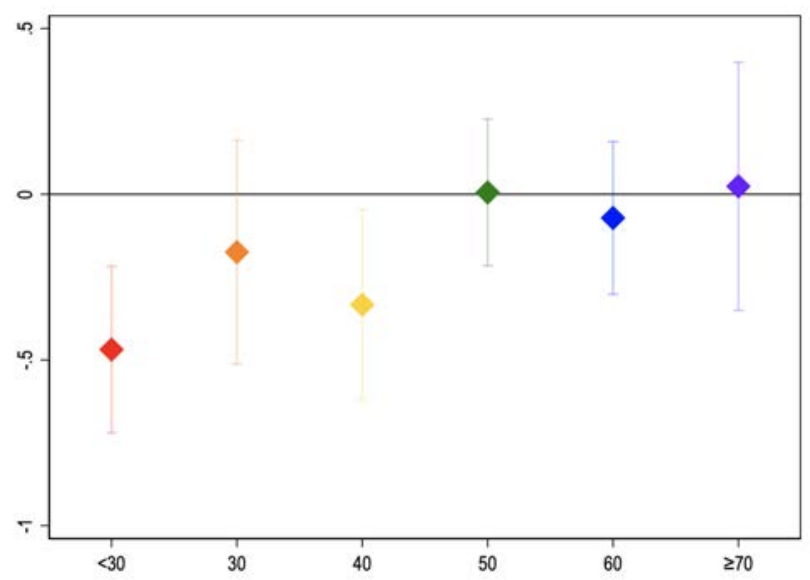

Notes: This figure displays the IV estimated impacts of exposure to PM2.5 above $25 \mu \mathrm{g} / \mathrm{m}^{3}$ by age, controlling for additional variables. Panel A controls for game fixed effects, and Panel B for a dummy indicating that the play is above the fifth for that user. The plotted coefficients in each panel are jointly estimated using 2SLS in a version of Equation (2) with interactions between the indicator of high PM2.5 and age groups. The instruments for these interactions are interactions of our original instrument with the bins for age groups. The vertical bars around the coefficients are $95 \%$ confidence intervals. 
Figure A.7: IV PM2.5 Impacts on Cognitive Function by Gender and Age

Panel A. Estimated Effects

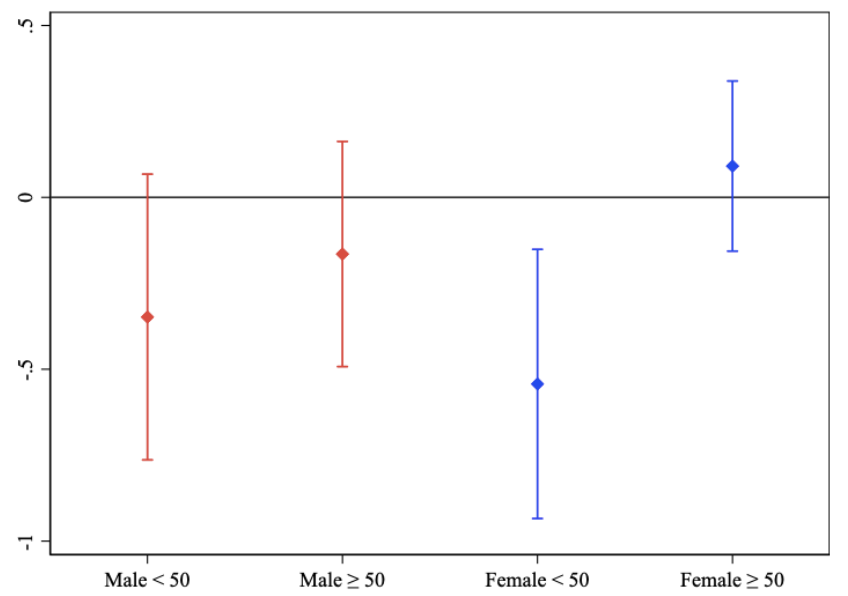

Panel B. Age Distribution and Male Shares

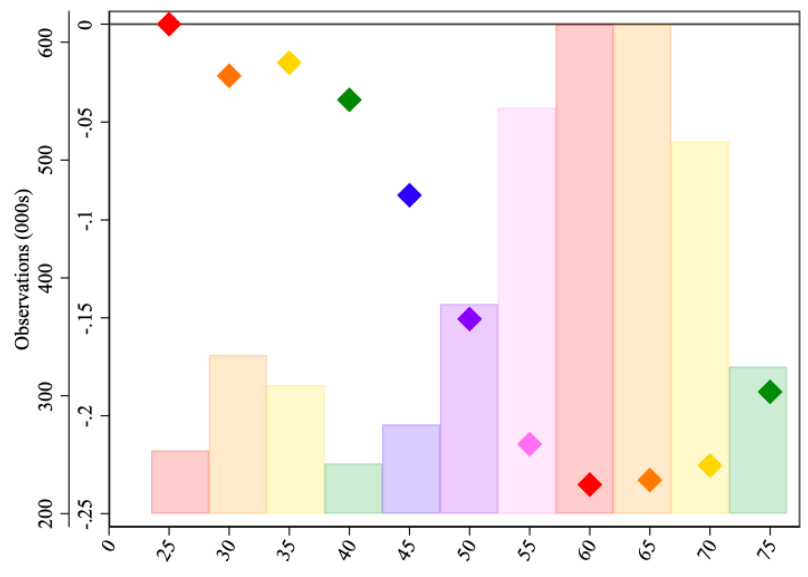

Notes: This figure displays the IV estimated impacts of exposure to PM2.5 above $25 \mu \mathrm{g} / \mathrm{m}^{3}$ by age-gender groups, and descriptive statistics on the age-gender distribution in our sample. In Panel A, the plotted coefficients are jointly estimated using 2SLS in a version of Equation (2) with interactions between the indicator of high PM2.5 and four age-gender groups - combinations of below/above 50 years old with male/female. The instruments for these interactions are interactions of our original instrument with indicators for age-gender groups. In Panel B, the bars depict the number of observations in each age range, and the markers show the change in the share of an age group that is male relative to male share of 20-25 year olds. 
Figure A.8: Learning Curves by Age

Panel A. Below vs. Above 50 Years Old

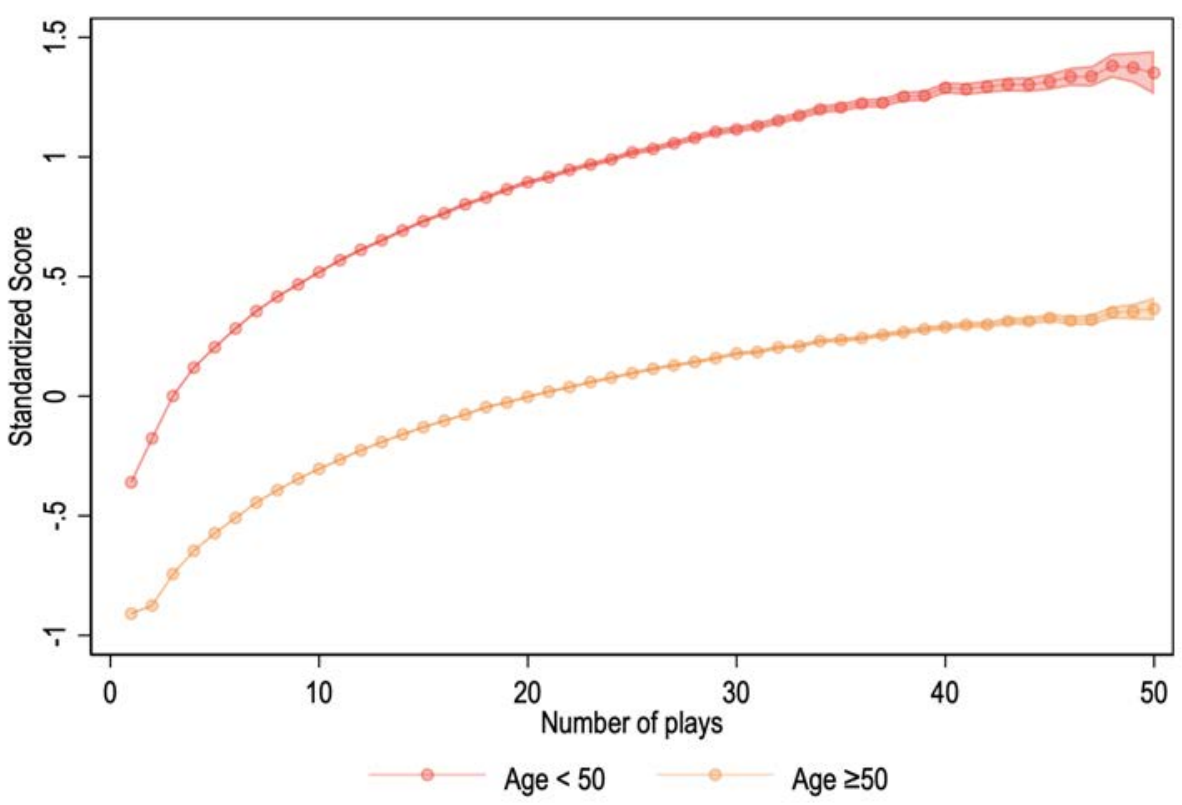

Panel B. Detailed Age Groups

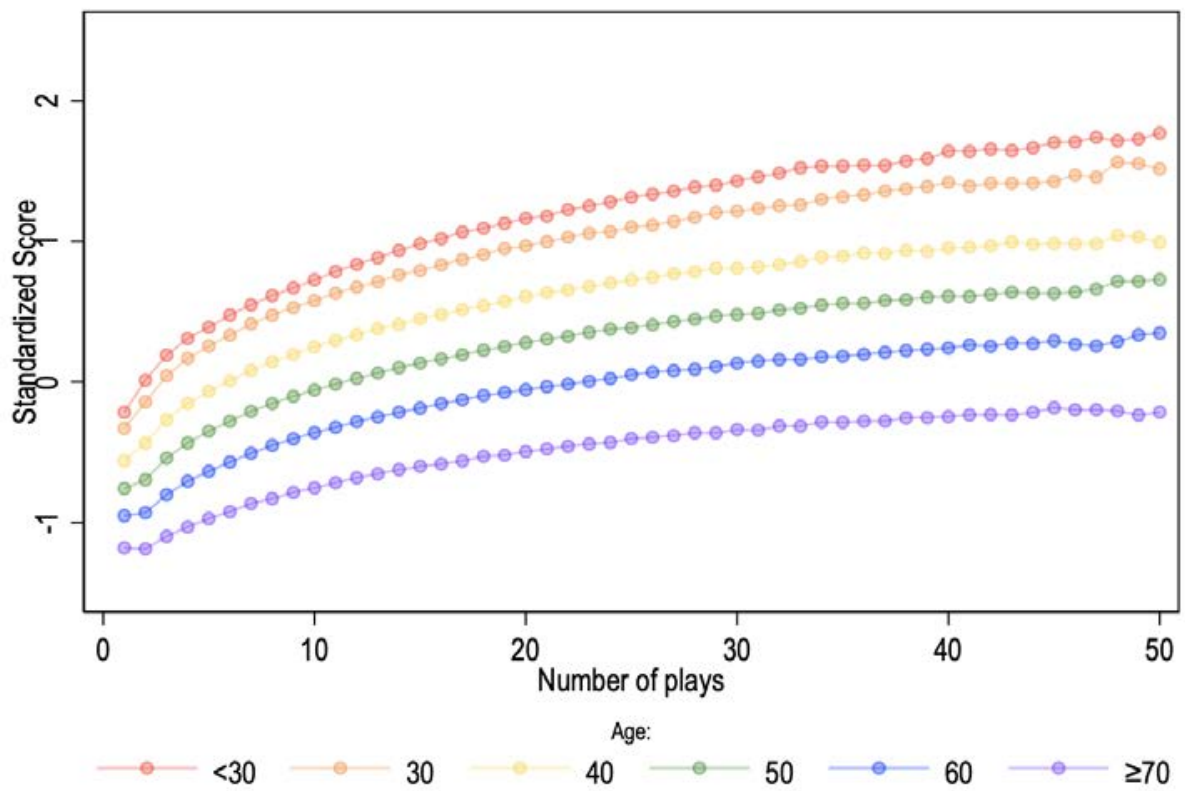

Notes: This figure displays the learning curve by age. Each panel plots coefficients of OLS regressions by age group of standardized scores on dummies for each number of plays. Panel A splits all users into two age groups - below vs. above 50 years old - and Panel B provides a more detailed age breakdown. 


\section{Figure A.9: IV PM2.5 Impacts on Specific Cognitive Domains - Robustness Check}

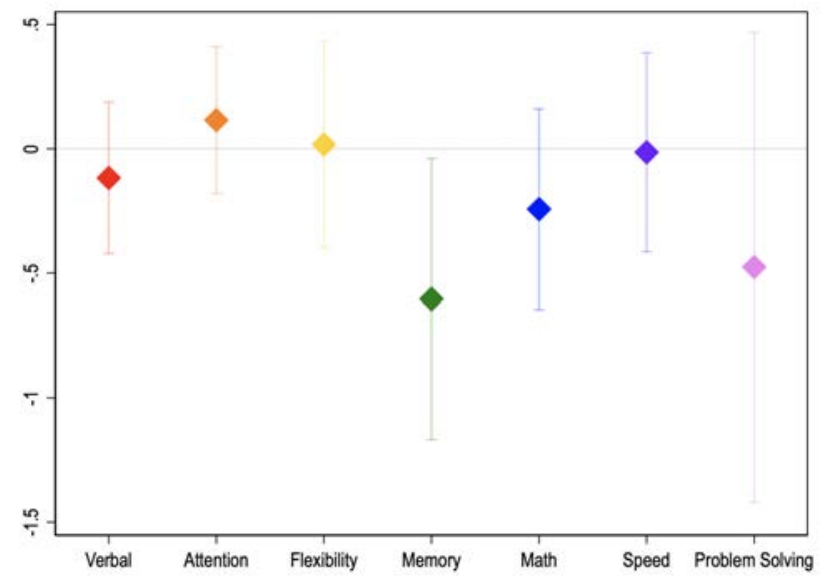

Notes: This figure displays the IV estimated impacts of exposure to PM2.5 above $25 \mu \mathrm{g} / \mathrm{m}^{3}$ by cognitive domain, controlling for a dummy indicating that the play is above the fifth for that user. The plotted coefficients are jointly estimated using 2SLS in a version of Equation (2) with interactions between the indicator of high PM2.5 and indicators for cognitive domains. The instruments for these interactions are interactions of our original instrument with indicators for cognitive domains. The vertical bars around the coefficients are $95 \%$ confidence intervals. 
Figure A.10: IV PM2.5 Impacts on Cognitive Function by Initial Ability - Robustness Checks

Panel A. Controlling for Game FE

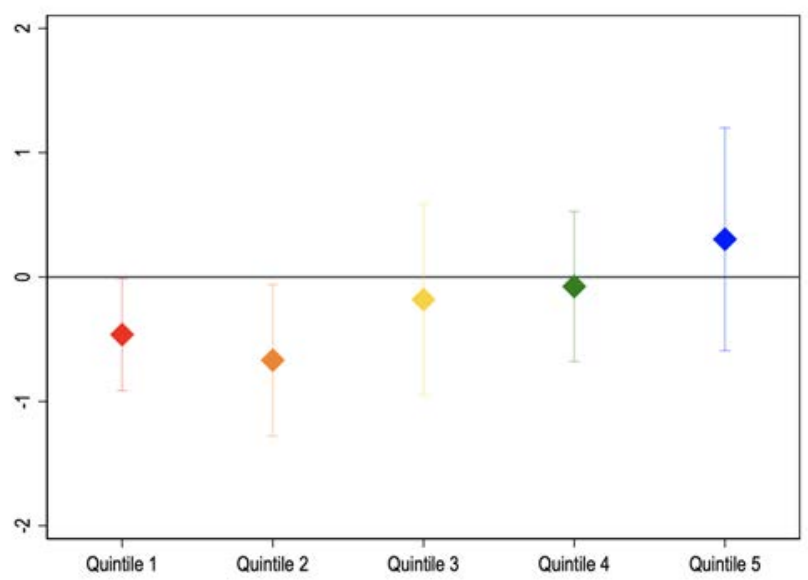

Panel B. Controlling for $>5$ Plays Dummy

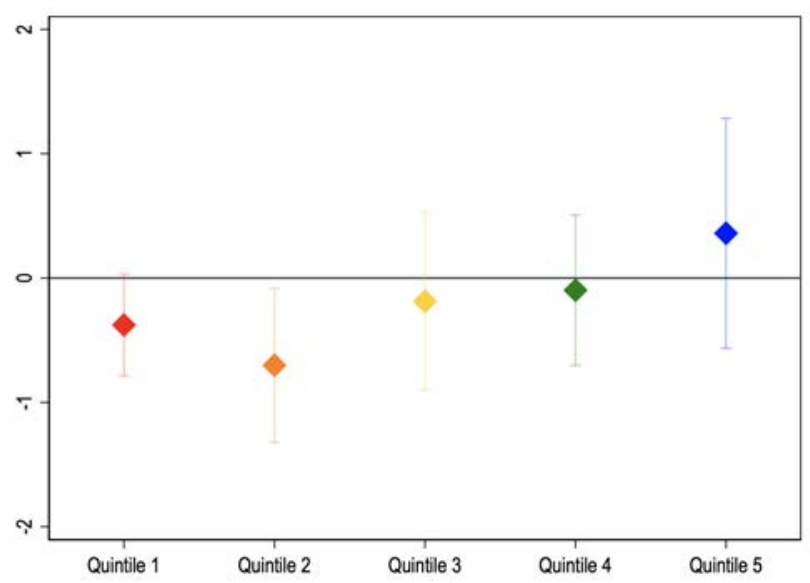

Notes: This figure displays the IV estimated impacts of exposure to PM2.5 above $25 \mu \mathrm{g} / \mathrm{m}^{3}$ by initial ability, controlling for additional variables. Panel A controls for game fixed effects, and Panel B for a dummy indicating that the play is above the fifth for that user. Our measure of ability is based on the first play in the memory game. In practice, it is the residualized score from Equation (4). The plotted coefficients in each panel are jointly estimated using 2SLS in a version of Equation (2) with interactions between the indicator of high PM2.5 and indicators for quintiles of initial ability. The instruments for these interactions are interactions of our original instrument with indicators for quintiles of initial ability. The vertical bars around the coefficients are $95 \%$ confidence intervals. 
Figure A.11: IV PM2.5 Impacts on Cognitive Function by Education

\section{Panel A. IV Estimated Effects}

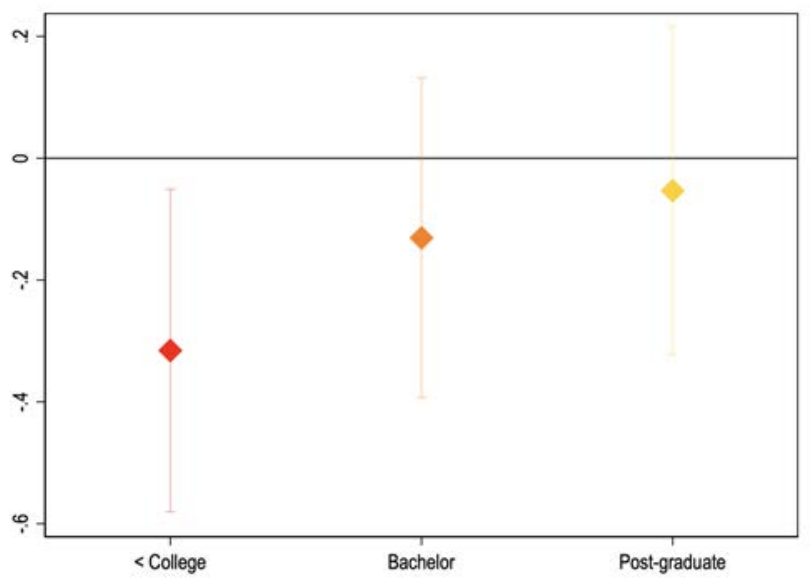

Panel B. Education and Initial Ability

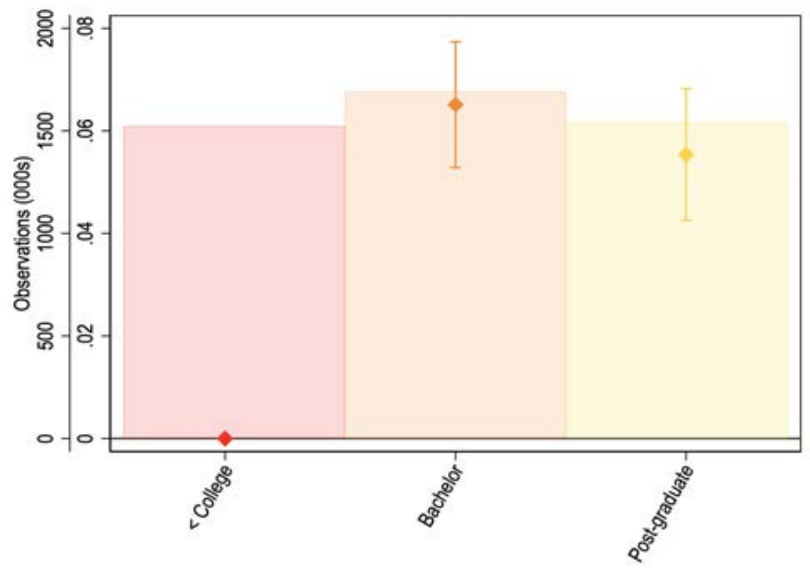

Notes: This figure displays the IV estimated impacts of exposure to PM2.5 above $25 \mu \mathrm{g} / \mathrm{m}^{3}$ by education, and descriptive statistics on educational attainment and initial ability in our sample. In Panel A, the plotted coefficients are jointly estimated using 2SLS in a version of Equation (2) with interactions between the indicator of high PM2.5 and three groups of educational attainment. The instruments for these interactions are interactions of our original instrument with indicators for groups of educational attainment. The vertical bars around the coefficients are $95 \%$ confidence intervals. In Panel B, the bars depict the number of observations in each education group, and the markers show the change in average initial ability for an education group relative to the category less than college degree. Our measure of ability is based on the first play in the memory game. In practice, it is the residualized score from Equation (4). 
Figure A.12: IV PM2.5 Impacts on Specific Cognitive Function by Learning Stage - Robustness Checks

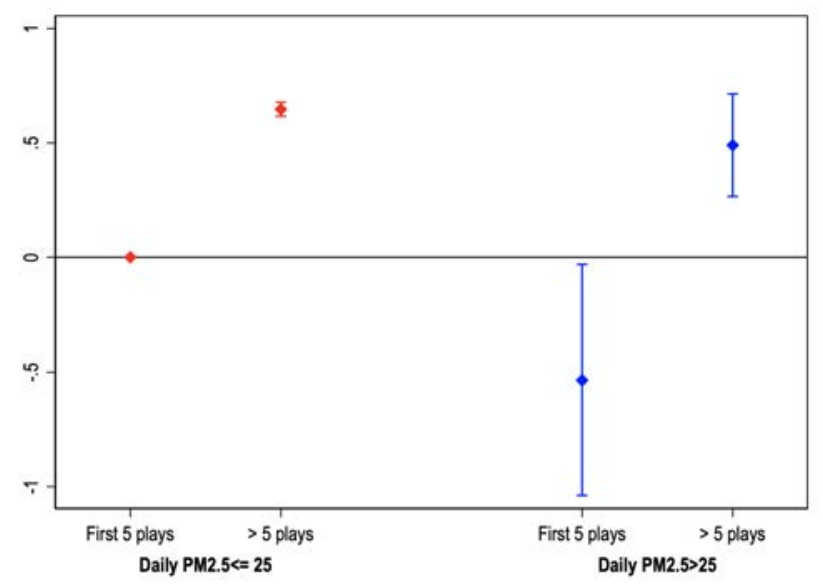

Notes: This figure displays the IV estimated impacts of exposure to PM2.5 above $25 \mu \mathrm{g} / \mathrm{m}^{3}$ by experience playing Lumosity games, controlling for game fixed effects. The plotted coefficients are jointly estimated using 2SLS in a version of Equation (2) with interactions between the indicator of high PM2.5 and indicators for the number of plays. The instruments for these interactions are interactions of our original instrument with indicators for categories of number of plays. The vertical bars around the coefficients are $95 \%$ confidence intervals. 
Table A.1: Lumosity Games

\begin{tabular}{lllc}
\hline Name & Domain & Skills & Levels \\
\hline Word Bubbles Rising & Verbal Fluency & vocabulary, reading comprehension & $\mathrm{Y}$ \\
Lost in Migration* & Selective Attention & selective attention, response inhibition & $\mathrm{N}$ \\
Brain Shift Task & Flexibility & task switching, classification & $\mathrm{N}$ \\
Memory Matrix & Working Memory & spatial recall, visual memory span & $\mathrm{Y}$ \\
Chalkboard Challenge & Math & quantitative, math, arithmetic reasoning & $\mathrm{N}$ \\
Speed Match\# & Speed & information processing & $\mathrm{N}$ \\
Pet Detective & Problem Solving & forming possible solutions, choosing the best & $\mathrm{Y}$ \\
\hline
\end{tabular}

Notes: This table presents the seven Lumosity games used in our analysis. The first column lists the game names. *Also known as the Flanker Task. \#Also known as the $\mathrm{N}$ back task. The second column lists the corresponding cognitive domains. The third column details the skills trained by the games. Lastly, the fourth column reports whether there are different levels of difficulty within the same game. 
Table A.2: Summary Statistics

\begin{tabular}{lc}
\hline \hline Variables & $(1)$ \\
\hline Average Age & 48.78 \\
& $(16.39)$ \\
Proportion Age $\geq 50$ & 0.542 \\
& $(0.498)$ \\
Proportion Age $\geq 65$ & 0.191 \\
& $(0.393)$ \\
Proportion of Males & 0.415 \\
& $(0.493)$ \\
Average Daily PM2.5 (in $\left.\mu g / m^{3}\right)$ & 5.850 \\
& $(3.146)$ \\
Maximum Number of Plays per Game & 20.32 \\
Proportion With Less Than College & $(13.75)$ \\
& 0.338 \\
Proportion With Bachelor Degree & $(0.473)$ \\
& 0.353 \\
Proportion With Post-graduate Degree & 0.310 \\
& $(0.462)$ \\
\hline Number of Lumosity Users & 0.367 \\
\hline \hline
\end{tabular}

Notes: This table reports summary statistics for our main sample. Standard deviations are reported in parentheses. 
Table A.3: IV PM2.5 Impacts on Cognitive Function Using Alternative Instruments

\begin{tabular}{lccc}
\hline \hline Panel A. IV Analysis Using Our Instrument & & \\
\hline Dep. Var.: Standardized Score & $(1)$ & $(2)$ & $(3)$ \\
& Daily PM $\left(\mu \mathrm{g} / \mathrm{m}^{3}\right)$ & $\mathbf{1}[$ Daily PM $>12]$ & $\mathbf{1}[$ Daily PM $>25]$ \\
\hline Daily PM2.5 & $-0.00486^{* *}$ & $-0.120^{* *}$ & $-0.183^{* *}$ \\
& $(0.00207)$ & $(0.0528)$ & $(0.0803)$ \\
\hline Observations & $4,667,636$ & $4,667,636$ & $4,667,636$ \\
First-stage F & 40.86 & 36.27 & 33.24 \\
\hline Panel B. IV Analysis Using Instruments à la Deryugina et al. $(2019)$ & $(2)$ & $(3)$ \\
\hline Dep. Var.: Standardized Score & $(1)$ & $(2)$ & $\mathbf{1}[$ Daily PM $>25]$ \\
& Daily PM $\left(\mu g / m^{3}\right)$ & $\mathbf{1}[$ Daily PM $>12]$ & -0.0083 \\
& $-0.0021^{* *}$ & $-0.0383^{* * *}$ & $(0.053)$ \\
\hline Daily PM2.5 & $(0.0009)$ & $(0.0144)$ & $3,940,666$ \\
& $3,940,666$ & $3,940,666$ & 2.479 \\
\hline Observations & 26,380 & 106.7 & \\
First-stage F &
\end{tabular}

Notes: This table reports the IV estimated impacts of exposure to PM2.5 on the standardized scores in Lumosity games using our instrument or the instruments à la Deryugina et al. (2019). Coefficients are estimated using 2SLS for Equation (2). This equation includes user fixed effects, month-by-year fixed effects, and meteorological controls. Meteorological controls include wind speed, precipitation and bins of daily maximum temperature. Panel A presents IV estimates arising from instrumenting daily PM2.5 with an indicator variable for whether the daily local wind direction is at the direction associated with the maximum potential for the transport of pollutants from other locations to a 3-digit ZIP code area where the Lumosity users are located. Panel B presents IV estimates instrumenting daily PM2.5 with interactions of 100 clusters of pollution monitors and 60-degree wind direction bins à la Deryugina et al. (2019). The first-stage F statistic is the Kleibergen-Paap rk Wald F statistic associated with the excluded instrument in the first stage. Standard errors double-clustered at the user and month-by-year levels are reported in parentheses (Cameron, Gelbach and Miller, 2011). *** denotes statistical significance at the $1 \%$ level, $* *$ at the $5 \%$ level, and * at the $10 \%$ level. 
Table A.4: IV PM2.5 Impacts on Cognitive Function by Age

\begin{tabular}{|c|c|}
\hline Dep. Var.: Standardized Score & $(1)$ \\
\hline \multicolumn{2}{|l|}{$\mathbf{1}[$ Daily PM2.5 $>25] \times$} \\
\hline $\mathbf{1}[$ Age $<30]$ & $\begin{array}{c}-0.608^{* * *} \\
(0.133) \\
{[0.001]} \\
\{11.22\}\end{array}$ \\
\hline $\mathbf{1}[$ Age $30-39]$ & $\begin{array}{l}-0.235 \\
(0.179) \\
{[0.341]} \\
\{9.33\}\end{array}$ \\
\hline $\mathbf{1}[$ Age 40-49] & $\begin{array}{c}-0.415^{* *} \\
(0.153) \\
{[0.018]} \\
\{8.94\}\end{array}$ \\
\hline $\mathbf{1}[$ Age 50-59] & $\begin{array}{c}0.037 \\
(0.117) \\
{[0.616]} \\
\{10.15\}\end{array}$ \\
\hline $\mathbf{1}$ [Age 60-69] & $\begin{array}{l}-0.097 \\
(0.122) \\
{[0.586]} \\
\{9.72\}\end{array}$ \\
\hline $\mathbf{1}[$ Age $\geq 70]$ & $\begin{array}{c}0.146 \\
(0.198) \\
{[0.586]} \\
\{11.45\}\end{array}$ \\
\hline Observations & $4,667,636$ \\
\hline
\end{tabular}

Notes: This table reports the IV estimated impacts of exposure to PM2.5 above $25 \mu \mathrm{g} / \mathrm{m}^{3}$ by age. Coefficients are jointly estimated using 2SLS in a version of Equation (2) with interactions between the indicator of high PM2.5 and age groups. The instruments for these interactions are interactions of our original instrument with indicators for age groups. The estimating equation includes user fixed effects, month-by-year fixed effects, and meteorological controls. Standard errors double-clustered at the user and month-by-year levels are reported in parentheses (Cameron, Gelbach and Miller, 2011). *** denotes statistical significance at the $1 \%$ level, ${ }^{* *}$ at the $5 \%$ level, and ${ }^{*}$ at the $10 \%$ level. Sharpened $q$ values accounting for multiple inference are reported in square brackets (Anderson, 2008). Conditional first-stage F statistics for weak instruments are reported in curly braces (Sanderson and Windmeijer, 2016). 
Table A.5: IV PM2.5 Impacts on Specific Cognitive Domains

\begin{tabular}{|c|c|c|}
\hline Dep. Var.: Standardized Score & (1) & $(2)$ \\
\hline \multicolumn{3}{|l|}{$\mathbf{1}[$ Daily PM2.5 > 25] $\times$} \\
\hline $\mathbf{1}[$ Verbal $]$ & $\begin{array}{c}-0.149 \\
(0.163) \\
{[1]} \\
\{8.287\}\end{array}$ & \\
\hline $\mathbf{1}[$ Attention $]$ & $\begin{array}{c}0.0738 \\
(0.137) \\
{[1]} \\
\{7.762\}\end{array}$ & \\
\hline $\mathbf{1}[$ Flexibility $]$ & $\begin{array}{c}-0.0632 \\
(0.237) \\
{[1]} \\
\{10.291\}\end{array}$ & \\
\hline $\mathbf{1}[$ Memory $]$ & $\begin{array}{c}-0.598^{* *} \\
(0.275) \\
{[0.304]} \\
\{20.239\}\end{array}$ & \\
\hline $\mathbf{1}[$ Math $]$ & $\begin{array}{c}-0.211 \\
(0.208) \\
{[1]} \\
\{10.358\}\end{array}$ & \\
\hline $\mathbf{1}[$ Speed] & $\begin{array}{c}-0.0859 \\
(0.206) \\
{[1]} \\
\{6.499\}\end{array}$ & \\
\hline $\mathbf{1}[$ Problem] Solving & $\begin{array}{c}-0.418 \\
(0.551) \\
{[1]} \\
\{5.420\}\end{array}$ & \\
\hline $\mathbf{1}$ [Non-memory domains] & & $\begin{array}{c}-0.135 \\
(0.0811) \\
{[0.077]} \\
\{42.873\}\end{array}$ \\
\hline $\mathbf{1}$ [Memory domain] & & $\begin{array}{c}-0.594^{* *} \\
(0.276) \\
{[0.077]} \\
\{26.787\}\end{array}$ \\
\hline Observations & $4,667,636$ & $4,667,636$ \\
\hline
\end{tabular}

Notes: This table reports the IV estimated impacts of exposure to PM2.5 above $25 \mu \mathrm{g} / \mathrm{m}^{3}$ by cognitive domain. Coefficients are jointly estimated using 2SLS in a version of Equation (2) with interactions between the indicator of high PM2.5 and cognitive domains. The instruments for these interactions are interactions of our original instrument with indicators for cognitive domains. The estimating equation includes user fixed effects, month-by-year fixed effects, and meteorological controls. Standard errors double-clustered at the user and month-by-year levels are reported in parentheses (Cameron, Gelbach and Miller, 2011). *** denotes statistical significance at the $1 \%$ level, ${ }^{* *}$ at the $5 \%$ level, and $*$ at the $10 \%$ level. Sharpened $q$ values accounting for multiple inference are reported in square brackets (Anderson, 2008). Conditional first-stage $\mathrm{F}$ statistics for weak instruments are reported in curly braces (Sanderson and Windmeijer, 2016). 
Table A.6: IV PM2.5 Impacts on Cognitive Function by Initial Ability

\begin{tabular}{|c|c|c|}
\hline Dep. Var.: Standardized Score & $(1)$ & $(2)$ \\
\hline \multicolumn{3}{|l|}{$\mathbf{1}[$ Daily PM2.5 > 25] $\times$} \\
\hline $\mathbf{1}$ [Ability Quintile 1] & $\begin{array}{c}-0.463^{* *} \\
(0.225) \\
{[0.124]} \\
\{8.294\}\end{array}$ & \\
\hline $\mathbf{1}$ [Ability Quintile 2] & $\begin{array}{c}-0.669^{* *} \\
(0.305) \\
{[0.124]} \\
\{8.336\}\end{array}$ & \\
\hline $\mathbf{1}$ [Ability Quintile 3] & $\begin{array}{c}-0.181 \\
(0.386) \\
{[0.924]} \\
\{6.772\}\end{array}$ & \\
\hline $\mathbf{1}$ [Ability Quintile 4] & $\begin{array}{r}-0.0760 \\
(0.302) \\
{[0.928]} \\
\{9.055\}\end{array}$ & \\
\hline $\mathbf{1}$ [Ability Quintile 5] & $\begin{array}{c}0.304 \\
(0.448) \\
{[0.924]} \\
\{9.220\}\end{array}$ & \\
\hline 1[Below Median Ability] & & $\begin{array}{c}-0.466^{* *} \\
(0.189) \\
{[0.035]} \\
\{30.744\}\end{array}$ \\
\hline $\mathbf{1}$ [Above Median Ability] & & $\begin{array}{c}0.00959 \\
(0.185) \\
{[0.921]} \\
\{35.390\}\end{array}$ \\
\hline Observations & 352,849 & 352,849 \\
\hline
\end{tabular}

Notes: This table reports the IV estimated impacts of exposure to PM2.5 above $25 \mu \mathrm{g} / \mathrm{m}^{3}$ by initial ability. Coefficients are jointly estimated using 2SLS in a version of Equation (2) with interactions between the indicator of high PM2.5 and quintiles of initial ability. The instruments for these interactions are interactions of our original instrument with indicators for quintiles of initial ability. The estimating equation includes user fixed effects, month-by-year fixed effects, and meteorological controls. Our measure of ability is based on the first play in the memory game. In practice, it is the residualized score from Equation (4). Standard errors double-clustered at the user and month-by-year levels are reported in parentheses (Cameron, Gelbach and Miller, 2011). *** denotes statistical significance at the $1 \%$ level, ${ }^{* *}$ at the $5 \%$ level, and $*$ at the $10 \%$ level. Sharpened $q$ values accounting for multiple inference are reported in square brackets (Anderson, 2008). Conditional first-stage F statistics for weak instruments are reported in curly braces (Sanderson and Windmeijer, 2016). 
Table A.7: IV PM2.5 Impacts on Specific Cognitive Function by Learning Stage

\begin{tabular}{cc}
\hline \hline Dep. Var.: Standardized Score & $(1)$ \\
\hline $\mathbf{1}$ [Daily PM2.5 $>25] \times$ & \\
$\mathbf{1}[$ Below 5 Plays] & $-0.506^{* *}$ \\
& $(0.250)$ \\
& {$[0.05]$} \\
& $\{24.614\}$ \\
$\mathbf{1}$ [Above 5 Plays] & -0.155 \\
& $(0.115)$ \\
& {$[0.077]$} \\
& $\{47.494\}$ \\
& 0 \\
$\mathbf{1}[$ Below 5 Plays] & $()$. \\
& {$[]$.} \\
$\mathbf{1}[$ Above 5 Plays] & $0.644^{* * *}$ \\
& $(0.0150)$ \\
\hline Observations & {$[0.001]$} \\
\hline \hline
\end{tabular}

Notes: This table reports the IV estimated impacts of exposure to PM2.5 above $25 \mu \mathrm{g} / \mathrm{m}^{3}$ by experience playing Lumosity games. Coefficients are jointly estimated using 2SLS in a version of Equation (2) with interactions between the indicator of high PM2.5 and two categories of number of plays - fewer or more than five plays. The coefficient of the indicator for below 5 plays is set to zero because it is the omitted category. The instruments for those interactions are interactions of our original instrument with indicators for categories of number of plays. The estimating equation includes user fixed effects, month-by-year fixed effects, and meteorological controls. Standard errors double-clustered at the user and month-by-year levels are reported in parentheses (Cameron, Gelbach and Miller, 2011). *** denotes statistical significance at the $1 \%$ level, ${ }^{* *}$ at the $5 \%$ level, and ${ }^{*}$ at the $10 \%$ level. Sharpened $q$ values accounting for multiple inference are reported in square brackets (Anderson, 2008). Conditional first-stage F statistics for weak instruments are reported in curly braces (Sanderson and Windmeijer, 2016). 


\section{Appendix B: Conceptual Framework}

Building on Graff Zivin and Neidell (2013), cognitive function can be expressed as a function of two components: the level of exposure to air pollution $p$, and a vector of attributes $x$ that may influence how exposure affects measures of cognition $S$ :

$$
S=f(p, x) .
$$

In our context, $p$ corresponds to ambient concentration of PM2.5 and $f($.$) translates$ $p$ into performance in various cognitive domains. Heterogeneity in environmental impacts may manifest through differences in levels of exposure $p$, and/or differences in the vector of mediating attributes $x$ that may interact with exposure through the cognitive function.

Building on Hsiang, Oliva and Walker (2019), if a change in exposure is relatively uniform across individuals - perhaps because it is marginal for all $i$-distributional effects may result from that change if marginal impacts

$$
\frac{\partial S_{i}}{\partial p}=\frac{\partial f\left(p_{i}, x_{i}\right)}{\partial p}
$$

differ across individuals. Heterogeneity in marginal impacts on cognition may arise from nonlinearities in the relationship between exposure and cognitive function, holding other factors constant, or from heterogeneity in an underlying attribute that controls how exposure translates into impacts. Designing environmental policy that addresses distributional effects may require understanding the source of this heterogeneity.

Heterogeneity in marginal impacts usually generates distributional effects of environmental change, because some individuals will benefit or be harmed more or less for incremental changes in environmental conditions. If marginal impacts are positively correlated with cognitive ability, for example, then policies that reduce exposure uniformly across a population will have regressive benefits since high-ability individuals benefit more from the policy. If marginal impacts are negatively correlated, such a policy would have progressive benefits. 